Thermal Science and Engineering Progress (Elsevier)

ISSN: 2451-9049

https://www.sciencedirect.com/journal/thermal-science-and-engineering-progress

Accepted September $23^{\text {rd }} 2020$

\title{
Hall current, viscous and Joule heating effects on steady radiative 2-D magneto-power-law polymer dynamics from an exponentially stretching sheet with power-law slip velocity: A numerical study
}

\author{
MD. Shamshuddin ${ }^{1}$, Sami Ullah Khan ${ }^{2}$, O. Anwar Bég ${ }^{3}$ and Tasveer A. Bég ${ }^{4}$ \\ ${ }^{1}$ Department of Mathematics, Vaagdevi College of Engineering, Warangal-506005, \\ Telangana State, India.
}

${ }^{2}$ Department of Mathematics, COMSATS University Islamabad, Sahiwal 57000, Pakistan.

${ }^{3}$ Professor and Director-Multi-Physical Engineering Sciences Group, Mechanical Engineering Department, School of Science, Engineering and Environment (SEE), University of Salford, Manchester, UK.

${ }^{4}$ Director, Engineering Mechanics Research, Israfil House, Dickenson Rd., Manchester, UK.

*Corresponding author: shamshuddin_md@vaagdevi.edu.in

\begin{abstract}
:
A mathematical model is developed for 2-D laminar, incompressible, electrically conducting non-Newtonian (Power-law) fluid boundary layer flow along an exponentially stretching sheet with power-law slip velocity conditions in the presence of Hall currents, transverse magnetic field and radiative flux. The secondary flow has been induced with appliance of Hall current. The distinguish features of Joule heating and viscous dissipation are included in the model since they are known to arise in thermal magnetic polymeric processing. Rosseland's diffusion model is employed for radiation heat transfer. The non-linear partial differential equations describing the flow (mass, primary momentum, secondary momentum and energy conservation) are transformed into non-linear ordinary differential equations by employing local similarity transformations. The non-dimensional nonlinear formulated set of equations is numerically evaluated with famous shooting algorithm by using MATLAB software. The validation of simulated numerical results has been completed with generalized differential quadrature (GDQ). Extensive visualization of primary and secondary velocities and temperature distributions for the effects of the emerging parameters is presented for both pseudo-plastic fluids $(n=0.8)$ and dilatant fluids $(n=1.2)$. The study is relevant to the manufacturing transport phenomena in electro-conductive polymers (ECPs).
\end{abstract}

KEYWORDS: Non-Newtonian power-law fluid, electro-conductive polymers (ECPs), Hall current, power-law slip velocity, stretching sheet. 


\section{INTRODUCTION}

Electro-conductive polymers (ECPs), also known as magnetic responsive materials, ECPs [15] becomes great topic of interest because of their prestigious involvement and applications in many technologies including surfacialcoatings, microfluidics, biomedical encapsulation etc. By merging magnetic and polymer materials composites can be produced with exceptional magnetic responsive features. Magnetic actuation provides unique capabilities as it can be spatially and temporally controlled, and can additionally be operated externally to the system, providing a non-invasive approach to remote control. Being diverse classes and types of magnetic responsive composite materials, which are deformed with utilization of magnetic impact, and are therefore ideal for next generation "smart" coatings for anticorrosion properties. Numerous types of ECP have been developed in recent years including biosensor liquids [5], polyaniline-polyacrylamide magnetic hydrogels [6], thermo-responsive shape memory magnetic polymers [7], programmable magnetic liquids [8], magnetoresponsive magnetorheological (MR) polymers [9] and ferromagnetic nanofluids [10].

The manufacture of these materials frequently utilizes stretching processes and heat transfer. Furthermore, the simulation of these fabrication processes fuses several branches of fluid dynamics including thermal convection, viscous magnetohydrodynamics and boundary layer theory. Precise calculations of the synthesis process can greatly assist in designing customized materials for different applications e.g. electroconductive smart coatings for aerospace and marine engineering components. Many researchers have therefore developed a variety of mathematical models for magnetic material transport phenomena from stretching sheets. These models have also featured a rich variety of non-Newtonian models and also diverse electromagnetic effects. Lawrence and Rao [11] studied non-similar two-dimensional viscous hydromagnetic flow of a short memory viscoelastic fluid from a linearly stretching sheet with heat source and viscous heating effects using the Chuang three-point backward finite difference scheme and a fourth order Runge-Kutta-Nachtsheim-Swigert shooting method. The Ostwald-DeWaele power-law model has also proved very popular in magnetic non-Newtonian fluid dynamics. Gorla et al. [12] derived closed-form similarity solutions for the steady three-dimensional power law fluid stretching boundary flow, evaluating in detail the momentum characteristics for powerlaw index and stretching ratio effects. Further studies of power-law dynamics include Andersson and Kumaran [13], Mehta and Rao [14] (including non-isothermal convection in porous media), Jumah and Mujumdar [15] (on thermo-solutal convection power law fluids under buoyancy forces in porous media) and Ariel [16] (on multiple numerical solutions of extending sheets). Andersson et al. [17] analyzed studied hydromagnetic power-law fluid over a stretching sheet, deriving exact similarity transformation, although they incorrectly computed flow acceleration with stronger magnetic field effect. Aneja and co-workers [18] employed the variational finite element method to compute the gyrotactic bioconvection in power-law magnetic flow from a tilted stretching sheet. They computed the correct response of increasing magnetic field, namely that it reduces momentum boundary layer thickness and decelerates the flow. Further studies deploying the power-law model include Chaube et al. [19] who simulated the propulsion of biorheological liquids in tapered deformable channels.

The above studies neglected Hall currents. Modern electromagnetic materials processing is increasingly deploying strong magnetic fields, which mobilize larger electromagnetic force and Hall currents. These modify the magnitude and direction of the current density and consequently. The involvement of Hall feature is associated with the current nature in conductor. In fact, the current is the tiny charges movement, typically holes, ions, electrons, 
etc. The Hall effect is generated via the lateral magnetic force acting on the drifting free charges. In parallel with experimental investigations, extensive theoretical and computational studies of hall current magnetofluid dynamics in materials manufacturing (among other applications) are specified in current decade. The Hall current initiates a secondary flow in such problems and this has been considered carefully in these studies. Representative works in this regard include El-Aziz [20] (who also considered thermal convection heat transfer in nanofluid stretching flow) and Ramesh et al. [21] (who analyzed magnetic viscoelastic twophase liquid pumping in Hall micropumps). Kamran et al. [22] employed the Optimal Homotopy Analysis Method (OHAM) to compute the collective impact of Hall current, Newtonian heating and second-order hydrodynamic slip on convective micropolar flow from a permeable stretching/shrinking sheet. Bhatti et al. [23] used the modified Zhou differential transform method to analyze the radiative-convective viscoplastic in aqueous electroconductive polymers (ECPs) from a stretching sheet with convective heating, Hall and Ion slip effects. Their results revealed that a lower profile of wall shear force is results with larger magnetic field features, where it is enhanced with higher values of Hall and ion-slip parameters and that the flow is secondary accelerated with higher values of rheological (Casson) fluid parameter. Other analyses of Hall current hydromagnetic flows include Béget al. [24] (on rotating channel-bound plasma flows), Sheri et al. [25] (on double diffusive convection in reactive inclined MHD Hall generators with Dufour cross diffusion effects) and very recently, Béget al. [24] (on non-isothermal micropolar heat fluctuation in a biomimetic Faraday-Hall current hybrid generator system).

By utilizing the magnetic impact in Newtonian fluid flows can also generate Ohmic dissipation. Also known as Joule thermoelectric heating, this effect can be exploited in many materials production systems with direct current (DC). These include silicate glass melt fabrication with electrode-dependent Joule dissipation which achieves more homogenous material constitution [25], electrochemical machining with electrolytic solutions [26] and magnetically responsive composite materials manufacturing [27]. Béget al. [28] developed one of the first mathematical models for combined Hall current, viscous features, ion-slip and Joule heating consequences in parallel plate time-dependent rheometry for magnetic liquids using an electrothermal network simulation code. Haldur and Lagoudas [31] investigated the deformation and flow in shape memory alloy melts with eddy current and Joule dissipation effects. Tripathi et al. [32] presented the first model for electro-osmotic nanofluid pumping in finite microfluidic channels with Joule dissipation effects. Abdel-Wahed [33] studied the thermo-convective ferromagnetic nanofluid flow from a rotating surface with Hall current and Joule heating. Mishraet al. [34] used the variation of parameter method (VPM) to obtain analytical power series solutions for non-Fourier MHD squeezing thermo-solutal flow between Riga plates (parallel electromagnetic sensor surfaces) with Joule and viscous heating effects.Babu and Narayana [35] used shooting quadrature to compute the hydromagnetic viscoelastic convection flow from a permeable stretching sheet with power law heat flux, heat source and Joule dissipation effects. Further studies include Shamshuddin et al. [36] (on time-dependent micropolar reactive thermo-solutal magnetic polymer processing from a tilted plane with Joule heating) and Amin [37] (on enrobing forced convection axisymmetric boundary layer flow along a cylinder in porous media with Joule and viscous heating).

High-temperature magnetic materials synthesis features radiative heat transfer in addition to conductive and convective heat transfer. This allows improved manipulation of material structure via energization of the flow field and is popular in other areas also including lasertreatment of ceramics, glass, liquid metals and optical materials. Some excellent works in this area include Mansour and Viskanta [38] and Rozzi et al. [39]. Lee and Viskanta [40] 
analysed the unsteady conductive-radiative cooling of an optical glass disk. The complexity of radiative heat transfer simulations in the presence of other effects (magnetic field, viscous flow, rheology etc.) requires simplification of the integro-differential radiative equation to simpler algebraic flux models. These flux approximations simultaneously reduce the dimensionality of the problem and make significant physical assumptions. A popular model for coupled radiative-convection in materials processing is the Rosseland diffusion flux model which applies to a "grey" fluid without scattering and can be derived via the exponential approximation of the kernel of the radiative integro-differential equation. Although generally limited to optically thick media, it provides satisfactory results. Mishra et al. [41] simulated thermal magnetic polymer processing flows by deploying the Rosseland flux model and Adomian decomposition method (ADM). They considered laminar, incompressible, reactive hydromagnetic flow of an electrically conducting non-Newtonian (Sisko) fluid from a bi-directional stretching sheet in a porous medium, showing that temperature is suppressed with increasing stretching sheet ratio whereas it is strongly enhanced with greater radiative parameter. They further observed that larger sheet stretching ratio weakly accelerates the primary flow throughout the boundary layer whereas it more dramatically accelerates the secondary flow and that both homogenous and heterogenous chemical reaction parameters weakly and more strongly, respectively, deplete concentration magnitudes. Imtiaz and Hayat [42] derived homotopy solutions for radiative magnetoconvective nanofluid flow on an exponentially stretching surface with dissipation. Béget al. [43] used Lie group algebra, Rosseland's model and MAPLE 13 shooting quadrature to analyzethermo-solutal radiative mixed magneto-convection slip boundary layer flow from a translating vertical surface with thermal convective boundary conditions. They focused on the "thermally thick" scenario (Biot number $>0.1$ ) and it is emphasized that with dominant of thermal radiation features improve the thickness of thermal boundary similar to the magnetic field impact. Numerous other multi-physical models for radiative convection flows in materials processing have been communicated based on some form of the Rosseland diffusion approximation and include Khan et al. [44] (on second law thermodynamic analysis of radiative viscoplastic nanofluid squeezing flow between radially extending disks), Cotrell [45] (on dissipative power-law fluids), Uddin et al. [46] (on nanofluid slip from extending/contracting sheets), Bég et al.[47] (on unsteady hydromagnetic reactive dissipative thermo-diffusive boundary layers), Uddin et al. [48] (on conjugate conduction, magnetoconvection, thermal radiation from a non-linearly stretching sheet) and Murthy et al. [49] (on second law analysis of radiative-convective Stokes polar duct flows).

Many key studies in rheology have established that polymers experience substantial hydrodynamic slip i.e. non-adherence to a boundary. The molten polymer slip appeared near the surface of solids when wall shear force is higher as compared to critical value.A seminal review of the many manifestations of this phenomenon has been given by Denn [50] who has highlighted the inter-dependence of extrusion instability and shear layer structures on slip effects. He has further noted that wall effects extending over lengths of the order of molecular dimensions or fractions of a micrometer may exert quantifiable modifications in polymeric material flows. Hatzikiriakos [51] has elaborated at great length that the classical no-slip boundary condition of fluid mechanics fails to be accurate for many molten polymer flows. He has also identified that in case of linear polymers, second critical wall shear stress value can arise wherein there is progression from weak to strong slip flow. Weak slip is associated with flow-induced chain detachment/desorption at the polymer interface. Strong slip is connected to chain disentanglement of the polymer chains in the bulk from a monolayer of polymer chains adsorbed at the interface. Both non-magnetic Newtonian and magnetohydrodynamic non-Newtonian slip flows have received some attention in the 
preceding decade. Bég et al. [52] used PSPICE network software to compute the Von Karman swirling magnetohydrodynamic slip flow from a permeable disk with significant radiative heat transfer and thermal conductivity variation. El Aziz and Afify [53] computed the Hiemenz magnetic slip flow of a viscoplastic fluid from a stretching surface with induction effects. Sahoo et al. [54] investigated the slip heat transfer of an electromagnetic third-grade fluid from a stretching sheet. They observed that increasing hydrodynamic slip decreases the momentum boundary layer thickness and increases the thermal boundary layer thickness, whereas higher rheological parameter has the contrary effect. Further studies of slip stretching surface flows include Wang [55] (Newtonian fluids), Halim et al. [56] (Maxwell viscoelastic nanofluid stagnation point stretching flow), Norouzi et al. [57] (Oldroyd-B curved tube slip flow), Noor et al. [58] (micropolar nanofluid stagnation slip flow and Shukla et al. [59] (magnetic nanofluid slip flow external to a curved body with entropy generation).

In the present article, as a simulation of thermal magnetic sheet polymeric processing, a mathematical model is developed for laminar, incompressible, magnetohydrodynamic (MHD) non-Newtonian (power-law) fluid flow from an exponentially stretching sheet with power-law slip velocity conditions in the presence of Hall currents, transverse magnetic field, radiative heat flux, viscous and Joule electro thermal dissipation effects. The boundary layer equations for mass, primary momentum, secondary momentum and energy conservation are transformed into non-linear ordinary differential equations using local similarity transformations. The non-dimensional nonlinear flow equations are numerically evaluated with employment of shooting technique. The results are also validated by employing generalized differential quadrature (GDQ), a modification of Bellman-Kalaba differential quadrature, is conducted. Extensive visualization of primary and secondary velocities and temperature distributions for the effects of key parameters is presented for both pseudoplastic fluids $(n=0.8)$ and dilatant fluids $(n=1.2)$. The novel and interesting aspects of current analysis is the utilization of Hall current and Joule dissipation consequences in addition to full verification with an alternative numerical method. This study therefore generalizes the work of Saleem and El Aziz [60] to consider both primary and secondary velocity fields.

\section{MATHEMATICAL MODEL}

Two-dimensional, incompressible, steady state, magnetohydrodynamic (MHD) flow of a magnetic non-Newtonian polymer over an exponentially stretching sheet subject to transverse magnetic field, Hall current, viscous and Joule heating is examined. The power-law model is adopted for rheological characteristics and Rosseland's diffusion approximation for radiative heat transfer. The non-uniform velocity of the exponentially stretching sheet (stretching is only in the $x$-direction) is assumed as $u_{w}(x)=U_{0} e^{x / L}$ where $U_{0}$ is the reference velocity, $L$ a characteristic length, keeping origin fixed in the fluid of the ambient temperature $T_{\infty}$. The positive $x$-axis is measured along the direction of the motion, the positive $y$-axis is taken normal to the surface of the sheet which lies in the $x-z$ plane as depicted in Figure 1. An external non-uniform magnetic field $B_{0} e^{x / 2 L}$ is imposed perpendicular to the surface of the sheet and $B_{0}$ is the reference magnetic field. The Cauchy stress tensor for a power-law fluid can be written as follows- see Chaube et al. [19]: 
$\tau_{i j}=-K\left|\sqrt{\frac{1}{2}(\Delta . \Delta)}\right|^{n-1} \Delta$,

The flow consistency index, symmetrical rate of deformation tensor and rheological powerlaw index are represented respectively as $K, \Delta, n$. Pseudoplastic fluids are described by $0<n<1$ and apparent viscosity decreases with increasing shear rate, $n>1$ describes dilatant fluids in which the apparent viscosity increases with increasing shear rate. $n=1$ corresponds to Newtonian fluids. The power-law fluid model has the following form of shear stress component along the $x$ and $z$-direction respectively[61]:

$$
\tau_{y x}=K\left|\frac{\partial u}{\partial y}\right|^{n-1} \frac{\partial u}{\partial y}, \quad \tau_{y z}=K\left|\frac{\partial w}{\partial y}\right|^{n-1} \frac{\partial w}{\partial y}
$$

The generalized Ohm's law which is modified to include Hall current is given by [24]:

$$
\mathbf{J}+\frac{\omega_{e} \tau_{e}}{\mathbf{B}}(\mathbf{J} \times \mathbf{B})=\sigma(\mathbf{E}+\mathbf{V} \times \mathbf{B}),
$$

Where $\mathbf{V} \equiv(u, 0, w), \mathbf{B} \equiv\left(0, B_{0}, 0\right), \mathbf{E} \equiv\left(E_{x}, E_{y}, E_{z}\right), \mathbf{J} \equiv\left(J_{x}, J_{y}, J_{z}\right), \sigma, \omega_{e}$ and $\tau_{e}$ denote respectively the velocity vector components, magnetic field vector components, electric field vector components, current density vector components, electric conductivity of the magnetic polymer, cyclotron frequency and electron collision time. In general, for an electrically conducting fluid, Hall currents are mobilized in the presence of strong magnetic field. The Hall effect is a direct consequence of Lorentz force, $j \times \mathbf{B}$. Hall current induces a secondary (cross) flow and the flow regime becomes two-dimensional. The conservation of electric current $\nabla . j=0$ results in $j_{y}=$ constant. Since the surface of the magnetic polymer sheet is electrically insulating, $j_{y}=0$ everywhere in the flow. Also, an absence of applied voltage implies that electric field vanishes, i.e. $\boldsymbol{E}=0$. The appropriate current density components (primary and secondary) are:

$$
j_{x}-m j_{z}=-\sigma w B_{0}, \quad j_{z}+m j_{x}=\sigma u B_{0},
$$

where $m=\omega_{e} \tau_{e}$ is the Hall parameter which represents Hall current. Solving $j_{x}$ and $j_{z}$ form above, we have:

$$
j_{x}=\frac{\sigma B_{0}}{1+m^{2}}(m u-w), \quad j_{z}=\frac{\sigma B_{0}}{1+m^{2}}(u+m w),
$$




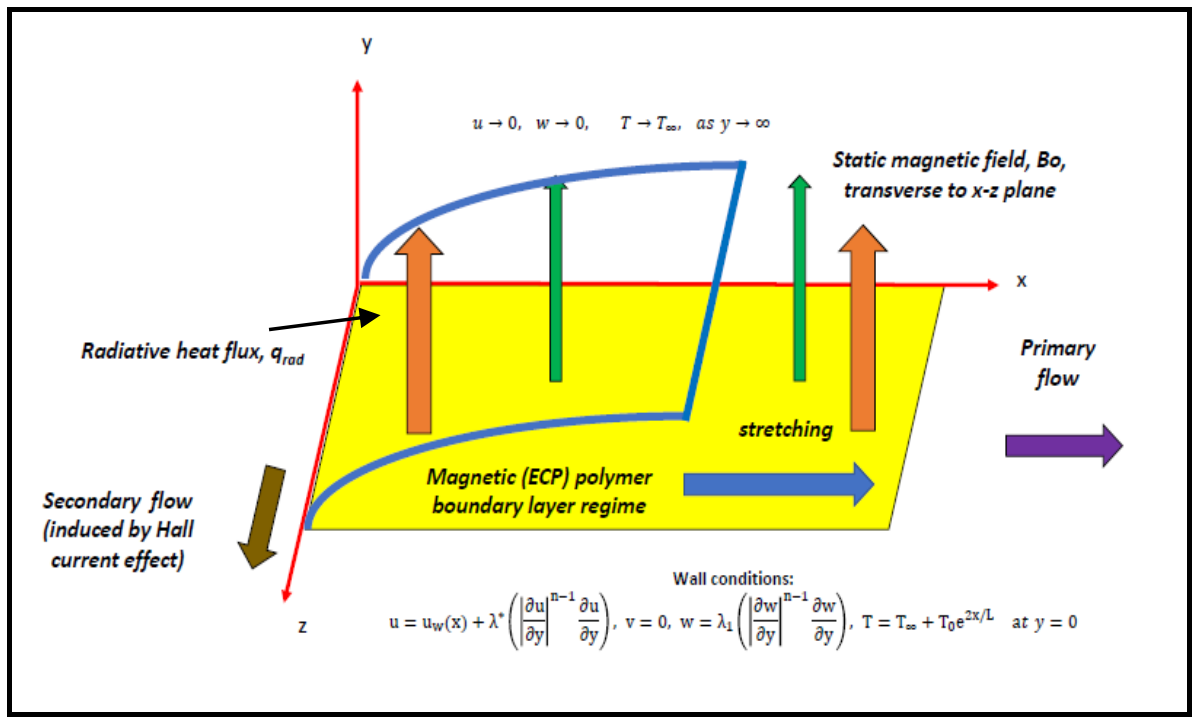

Figure 1: Geometrical model of magnetic polymer stretching flow with Hall current

The governing equations for the optically dense stretching regime can be shown to take the form:

$$
\begin{aligned}
& \frac{\partial u}{\partial x}+\frac{\partial v}{\partial y}=0 \\
& u \frac{\partial u}{\partial x}+v \frac{\partial u}{\partial y}=\frac{K}{\rho} \frac{\partial}{\partial y}\left(\left|\frac{\partial u}{\partial y}\right|^{n-1} \frac{\partial u}{\partial y}\right)+g \beta_{T}\left(T-T_{\infty}\right)-\frac{\sigma B_{0}^{2}}{\rho\left(1+m^{2}\right)}(u+m w), \\
& u \frac{\partial w}{\partial x}+v \frac{\partial w}{\partial y}=\frac{K}{\rho} \frac{\partial}{\partial y}\left(\left|\frac{\partial w}{\partial y}\right|^{n-1} \frac{\partial w}{\partial y}\right)+\frac{\sigma B_{0}^{2}}{\rho\left(1+m^{2}\right)}(m u-w) \\
& u \frac{\partial T}{\partial x}+v \frac{\partial T}{\partial y}=\alpha \frac{\partial^{2} T}{\partial y^{2}}-\frac{1}{\rho c_{p}} \frac{\partial q_{r a d}}{\partial y}+\frac{\sigma B_{0}^{2}}{\rho c_{p}} u^{2}+\frac{K}{\rho c_{p}}\left|\frac{\partial u}{\partial y}\right|^{n+1},
\end{aligned}
$$

In Eqns. (6)-(9) $u$ and $v$ designate the component of the velocities, $T$ is temperature, $k$ signifies the thermal conductivity, $\beta$ is the coefficient of thermal expansion, $c_{p}$ signifies specific heat at constant pressure and $q_{\text {rad }}$ radiative heat flux. The appropriate boundary conditions for regime are:

$$
\begin{array}{ccc}
u=u_{w}(x)+\lambda^{*}\left(\left|\frac{\partial u}{\partial y}\right|^{n-1} \frac{\partial u}{\partial y}\right), v=0, w=\lambda_{1}\left(\left|\frac{\partial w}{\partial y}\right|^{n-1} \frac{\partial w}{\partial y}\right), T=T_{\infty}+T_{0} e^{2 x / L} & \text { at } y=0, \\
u \rightarrow 0, \quad w \rightarrow 0, & T \rightarrow T_{\infty}, & \text { as } y \rightarrow \infty,
\end{array}
$$

Further, $\lambda^{*}, \lambda_{1}$ are primary and secondary hydrodynamic slip coefficients. The radiative heat flux is simplified by employing the Rosseland approximation, following Bég et al. [47] for an optically thick fluid with the following expression:

$q_{\text {rad }}=-\frac{4 \sigma^{*}}{3 k^{*}} \frac{\partial T^{4}}{\partial y}=-\frac{16 \sigma^{*}}{3 k^{*}} \frac{\partial}{\partial y}\left(T^{3} \frac{\partial T}{\partial y}\right)$ 
Similarity transformations of Eqns. (6)-(11) of the following form are proposed [60]:

$$
\begin{aligned}
& \psi=\left(\frac{2 K L U_{0}^{2 n-1}}{\rho}\right)^{1 /(n+1)} e^{\left(\frac{2 n-1}{n+1}\right) \frac{x}{L}} f(\eta), u=U_{0} e^{\frac{x}{L}} f^{\prime}(\eta), \\
& v=-\left(\frac{2 K U_{0}^{2 n-1}}{\rho L^{n}}\right)^{1 /(n+1)} e^{\left(\frac{2 n-1}{n+1}\right) \frac{x}{L}}\left[\frac{2 n-1}{n+1} f(\eta)+\frac{2-n}{n+1} \eta f^{\prime}(\eta)\right], \\
& w=U_{0} e^{\frac{x}{L}} g(\eta), \quad \theta=\frac{T-T_{\infty}}{T_{w}-T_{\infty}}, \quad \eta=y\left(\frac{\rho U_{0}^{2-n}}{2 K L}\right)^{1 /(n+1)} e^{\left(\frac{2-n}{n+1}\right) \frac{x}{L}}
\end{aligned}
$$

where stream function $(\psi)$ successfully satisfies the continuity equation with relation $u=\partial \psi / \partial y$ and $v=-\partial \psi / \partial x$. Substitution of Eqns. (11) - (12) in Eqns. (6)-(10), leads to the following self-similar boundary layer equations:

\section{Primary}

$$
\frac{n}{2}\left|f^{\prime \prime}\right|^{n-1} f^{\prime \prime \prime}+\left(\frac{2 n-1}{n+1}\right) f f^{\prime \prime}-f^{\prime 2}-\frac{M}{1+m^{2}}\left(f^{\prime}+m g\right)+\delta \theta=0,
$$

\section{Secondary}

$$
\frac{n}{2}\left|g^{\prime}\right|^{n-1} g^{\prime \prime}+\left(\frac{2 n-1}{n+1}\right) f g^{\prime}+\frac{M}{1+m^{2}}\left(m f^{\prime}-g\right)-f^{\prime} g=0,
$$

\section{Energy}

$$
\left(1+\frac{4}{3} R\right) \theta^{\prime \prime}+\operatorname{Pr}\left(\frac{2 n-1}{n+1}\right) f \theta^{\prime}-2 \operatorname{Pr} f^{\prime} \theta+\operatorname{Pr} E c\left[M f^{\prime 2}+\frac{1}{2}\left|f^{\prime \prime}\right|^{n+1}\right]=0,
$$

The boundary conditions at the wall and in the freestream are:

$$
\begin{aligned}
& f(0)=0, \quad f^{\prime}(0)=1+\lambda\left|f^{\prime \prime}(0)\right|^{n-1} f^{\prime \prime}(0), \quad g(0)=\lambda\left|g^{\prime}(0)\right|^{n-1} g^{\prime}(0), \theta(0)=1, \\
& f^{\prime}(\infty) \rightarrow 0, \quad g(\infty) \rightarrow 0, \quad \theta(\infty) \rightarrow 0,
\end{aligned}
$$

Here primes denote differentiation with respect to $\eta$. The non-dimensional parameters featuring in Eqns. (13)- (16) are the magnetic body force parameter $M$, mixed convection parameter, $\delta$ (a function of local Grashof number $G r_{x}$ and Reynolds number Re), thermal radiation parameter, $\mathrm{R}$, generalized Prandtl number, $\operatorname{Pr}$ (a function of local Reynolds number, $R e_{x}$ ), thermal diffusivity $\alpha$, Eckert number $E c$ and generalized slip parameter $\lambda$ are defined as follows:

$$
\begin{aligned}
& M=\frac{\sigma B_{0}^{2} L}{\rho U_{0}^{2}}, \delta=\frac{G r_{x}}{\operatorname{Re}^{2}}=\frac{g \beta L T_{0}}{U_{0}^{2}}, \quad G r_{x}=\frac{g \beta T_{0} L^{3} \rho^{2}}{K^{2}} e^{2 x / L}, \quad \operatorname{Re}=\frac{\rho L u_{w}(x)}{K}, \\
& R=\frac{4 \sigma^{*} T_{\infty}^{3}}{k k^{*}}, \operatorname{Pr}=\frac{u_{w} L}{\alpha}\left(\frac{\operatorname{Re}_{x}}{2}\right)^{-\left(\frac{2}{n+1}\right)}, \operatorname{Re}_{x}=\frac{\rho u_{w}^{2-n} L^{n}}{K}, \alpha=\frac{k}{\rho c_{p}}, E c=\frac{u_{w}^{2}}{\left(T_{w}-T_{\infty}\right) c_{p}}, \\
& \lambda=\lambda^{*}\left(\frac{\rho u_{w}^{2 n-1}}{2 K L}\right)^{\frac{1}{n+1}}
\end{aligned}
$$


Now the physical quantities from the engineering point of view are primary skin friction coefficient and Nusselt number which can be estimated by the following expressions:

$$
\begin{aligned}
& \tau_{w}=\left(K\left|\frac{\partial u}{\partial y}\right|^{n-1} \frac{\partial u}{\partial y}\right)_{y=0}=\frac{K u_{w}^{n}}{L^{n}}\left(\frac{\operatorname{Re}_{x}}{2}\right)^{\frac{1}{n+1}}\left|f^{\prime \prime}(0)\right|^{n-1} f^{\prime \prime}(0), \\
& C f_{x}=\frac{2 \tau_{w}}{\rho u_{w}^{2}}=\left(\frac{\operatorname{Re}_{x}}{2}\right)^{-\frac{1}{n+1}}\left|f^{\prime \prime}(0)\right|^{n-1} f^{\prime \prime}(0) \\
& N u_{x}=-\frac{L}{T_{w}-T_{\infty}}\left(1+\frac{16 \sigma^{*} T_{\infty}^{3}}{3 k k^{*}}\right)\left(\frac{\partial T}{\partial y}\right)_{y=0}=-\left(\frac{\operatorname{Re}_{x}}{2}\right)^{\frac{1}{n+1}}\left(1+\frac{4}{3 R}\right) \theta^{\prime}(0)
\end{aligned}
$$

\section{MATLAB QUADRATURE NUMERICAL SOLUTIONS}

Since the boundary conditions for the formulated problem i.e. Eqns. (13)-(16) are complicated and owing to very high nonlinearity, purely analytical solutionsare not possible. Therefore, an efficient shooting technique is implemented to achieve numerical solutions. The transformed nonlinear boundary value problem features 8 parameters - magnetic parameter, $M$, mixed convection parameter, $\delta$, thermal radiation parameter, $R$, Prandtl number $\operatorname{Pr}$, Hall current constant $m$, Eckert number $E c$, generalized slip parameter, $\lambda$ and power-law index, $n$. The higher order system is converted into a system of multiple first oder equations by via following assumptions:

$$
\begin{aligned}
y_{1}= & f, y_{2}=f^{\prime}, y_{3}=f^{\prime \prime}, y_{4}=g, y_{5}=g^{\prime}, y_{6}=\theta, y_{7}=\theta, \\
y_{3}^{\prime}= & \frac{\left[-\left(\frac{2 n-1}{n+1}\right) y_{1} y_{3}+y_{2}^{2}+\frac{M}{1+m^{2}}\left(y_{2}+m y_{4}\right)-\delta y_{6}\right]}{\frac{n}{2}\left|y_{3}\right|^{n-1}}, \\
y_{5}^{\prime}= & \frac{\left[-\left(\frac{2 n-1}{n+1}\right) y_{1} y_{5}-\frac{M}{1+m^{2}}\left(m y_{2}-y_{4}\right)+y_{2} y_{4}\right]}{\frac{n}{2}\left|y_{5}\right|^{n-1}}, \\
y_{7}^{\prime}= & \frac{-\operatorname{Pr}\left(\frac{2 n-1}{n+1}\right) y_{1} \theta^{\prime}+2 \operatorname{Pr} y_{2} y_{6}-\operatorname{Pr} E c\left[M y_{2}^{2}+\frac{1}{2}\left|y_{3}\right|^{n+1}\right]}{\left(1+\frac{4}{3} R\right)},
\end{aligned}
$$

The boundary conditions assume the form:

$$
\begin{aligned}
& y_{1}(0)=0, \quad y_{2}(0)=1+\lambda\left|y_{3}(0)\right|^{n-1} y_{3}(0), \quad y_{4}(0)=\lambda\left|y_{5}(0)\right|^{n-1} y_{5}(0), \quad y_{6}(0)=1, \\
& y_{2}(\infty) \rightarrow 0, \quad y_{4}(\infty) \rightarrow 0, \quad y_{6}(\infty) \rightarrow 0,
\end{aligned}
$$

An iterative process has been utilized and the accuracy of solution is examined up to a tolerance of $10^{-6}$. 


\section{VALIDATION WITH GENERALIZED DIFFERENTIAL QUADRATURE (GDQ)}

After formulating the novel flow problem equations, aim here to report the numerical solution which has not been presented in the literature yet. It is remarked that no such solution is computed by researchers to validate the shooting method numerical values. On this end, the Eqs. (13-15) are tackled with generalized differential quadrature (GDQ). The basic idea of this scheme is based on differentiation of involved function w.r.t. space variable on given points is approximated as a weighted linear sum at the selected points in the variable domain. The fundamental work on GDQ procedure was followed by Shu et al. [61] to modify the Bellman differential quadrature (DQM) method which is associated to integral quadrature and was established in 1972.It generally approximates the differentiation of function with respect to space variables at a sample grid point as a weighted linear summation of all the values of function at all grid points in the domain. The weight coefficients for GDQ are computed with appliance of higher order polynomial approximation and linear vector space. For first order derivates, the weight coefficients are computed with help of algebraic formulation while recurrence relationship is used to simulate the weight coefficients for second order derivates. According to Shu et al. [61], both GDQ approach and higher order finite difference approximations are almost similar tasks. This technique has been employed in viscoelastic flows [62], natural convection flows [63], viscous magnetohydrodynamics [64] and nanofluid dynamics [65].In order to present the simulation procedure in GDQ, we assume a general function $f(\xi)$ in given domain $0<\xi \leq a$. According to this method, function $f$

$(\xi)$ is approximated via following relations:

$$
\left.\frac{\partial^{r} f(\xi)}{\partial \xi^{r}}\right|_{\xi, \tau=\xi_{i}}=\sum_{m=1}^{N_{\xi}} A_{i m}^{(r)} f\left(\xi_{m}\right)=\sum_{m=1}^{N_{\xi}} A_{i j}^{(r)} f_{m}, \quad i=1,2, \ldots \ldots, N_{\xi} .
$$

Therefore, the weight coefficients for first order derivates in $\xi_{i}$ direction can be depicted with help of formula ([64]).

$$
A_{i j}=\left\{\begin{array}{ll}
-\sum_{j=1, i \neq j}^{N_{\xi}} A_{i j}, & i=j, \\
\frac{1}{a} \frac{M\left(\xi_{i}\right)}{\left(\xi_{i}-\xi_{j}\right) M\left(\eta_{i}\right)}, & i \neq j,
\end{array} \quad i, j=1,2, \ldots N_{\xi}, \quad M\left(\xi_{i}\right)=\prod_{j=1, i \neq j}^{N_{\xi}}\left(\xi_{i}-\xi_{j}\right)\right.
$$

Moreover, for higher order derivatives, the weight coefficients are developed by using following relations:

$$
\left[A_{i j}^{(r)}\right]=\left[A_{i j}^{(r-1)}\right]\left[A_{i j}\right]=\left[A_{i j}\right]\left[A_{i j}^{(r-1)}\right]
$$

The Chebyshev-Gauss-Lobatto grid distribution formula is

$$
\frac{\xi_{i}}{a}=\frac{1}{2}\left[1-\cos \left(\frac{i-1}{N_{\xi}-1} \pi\right)\right] \quad i=1,2, \ldots ., N_{\xi},
$$

Following to GDQ procedure, one can successfully obtained the discretized governing equations and boundary conditions which are being not presented here for brevity. During the formulation procedure, parameter $B$ (second order weighting coefficients) and $C$ (third order weighting coefficients) arises. The similarity flow variables $\left(f_{i}, g_{i}, \theta_{i}\right.$ ) values at various nodes can be resulted. These relations are effective to compute the relations for wall shear stress and local Nusselt number. Comparisons of the MATLAB shooting solutions and the GDQ code (which is executed on an SGI Octane desk workstation and takes about 110 seconds to converge) are shown in Tables 1 and 2 for primary skin friction and local Nusselt number. 
Table 1: Variation in primaryskin friction coefficient when $R=0.5, \operatorname{Pr}=0.5, E c=0.3$

\begin{tabular}{|c|l|l|l|c|c|c|c|}
\hline \multicolumn{3}{|c|}{ Parameters } & \multicolumn{5}{c|}{$\left(\mathrm{Re}_{x} / 2\right)^{-\frac{1}{n+1}}\left|f^{\prime \prime}(0)\right|^{n-1} f^{\prime \prime}(0)$} \\
\hline$\lambda$ & $\delta$ & $M$ & $m$ & $n=0.8$ (MATLAB) & $n=0.8($ GDQ) & $n=1.2$ (MATLAB) & $n=1.2$ (GDQ) \\
\hline 0.0 & 0.2 & 0.5 & 0.2 & 0.66295 & 0.66288 & 0.51544 & 0.51549 \\
0.2 & & & & 0.638456 & 0.63849 & 0.48680 & 0.48674 \\
0.4 & & & & 0.51484 & 0.51481 & 0.42622 & 0.42619 \\
\hline 0.1 & 0.0 & & & 0.64465 & 0.64462 & 0.50542 & 0.50538 \\
& 0.3 & & & 0.668690 & 0.66868 & 0.54309 & 0.54311 \\
& 0.5 & & & 0.69328 & 0.69331 & 0.58733 & 0.58740 \\
\hline \multirow{2}{*}{0.0} & & 0.66497 & 0.66486 & 0.54235 & 0.54234 \\
& & 0.4 & & 0.628335 & 0.62834 & 0.52489 & 0.52481 \\
& & 0.6 & & 0.61178 & 0.61172 & 0.50387 & 0.50379 \\
\hline & & 0.1 & 0.65210 & 0.65204 & 0.53087 & 0.53078 \\
& & 0.4 & 0.66678 & 0.66671 & 0.55678 & 0.55673 \\
& & 0.6 & 0.68765 & 0.68763 & 0.57986 & 0.57981 \\
\hline
\end{tabular}

Table 2: Variation in local Nusselt number

\begin{tabular}{|c|l|l|l|l|l|l|c|c|c|c|}
\hline \multicolumn{9}{|c|}{ Parameters } & \multicolumn{5}{c|}{$N u_{x}=-\left(\mathrm{Re}_{x} / 2\right)^{\frac{1}{n+1}}(1+(4 / 3 R))$} \\
\hline Pr & $\lambda$ & $\delta$ & $M$ & $R$ & $E c$ & $m$ & $\begin{array}{c}n=0.8 \\
\text { MATLAB }\end{array}$ & $\begin{array}{c}n=0.8 \\
\text { GDQ }\end{array}$ & $\begin{array}{c}n=1.2 \\
\text { MATLAB }\end{array}$ & $\begin{array}{c}n=1.2 \\
\text { GDQ }\end{array}$ \\
\hline 0.1 & 0.1 & 0.2 & 0.5 & 0.3 & 0.4 & 0.3 & 0.72658 & 0.72651 & 0.64567 & 0.64561 \\
0.5 & & & & & & & 0.78207 & 0.78202 & 0.67778 & 0.67771 \\
& & & & & & & 0.82507 & 0.82511 & 0.69409 & 0.69412 \\
\hline 0.5 & 0.0 & & & & & & 0.68637 & 0.68642 & 0.51573 & 0.51577 \\
& 0.2 & & & & & & 0.71974 & 0.71982 & 0.55582 & 0.55584 \\
& 0.4 & & & & & & 0.73629 & 0.73627 & 0.59743 & 0.59748 \\
\hline & 0.1 & 0.0 & & & & & 0.66518 & 0.66516 & 0.51758 & 0.51752 \\
& & 0.3 & & & & & 0.6281222 & 0.62812 & 0.49436 & 0.49438 \\
& & 0.5 & & & & & 0.60038 & 0.60032 & 0.46892 & 0.46886 \\
\hline & & & 0.0 & & & & 0.70549 & 0.70543 & 0.59398 & 0.59402 \\
\hline
\end{tabular}




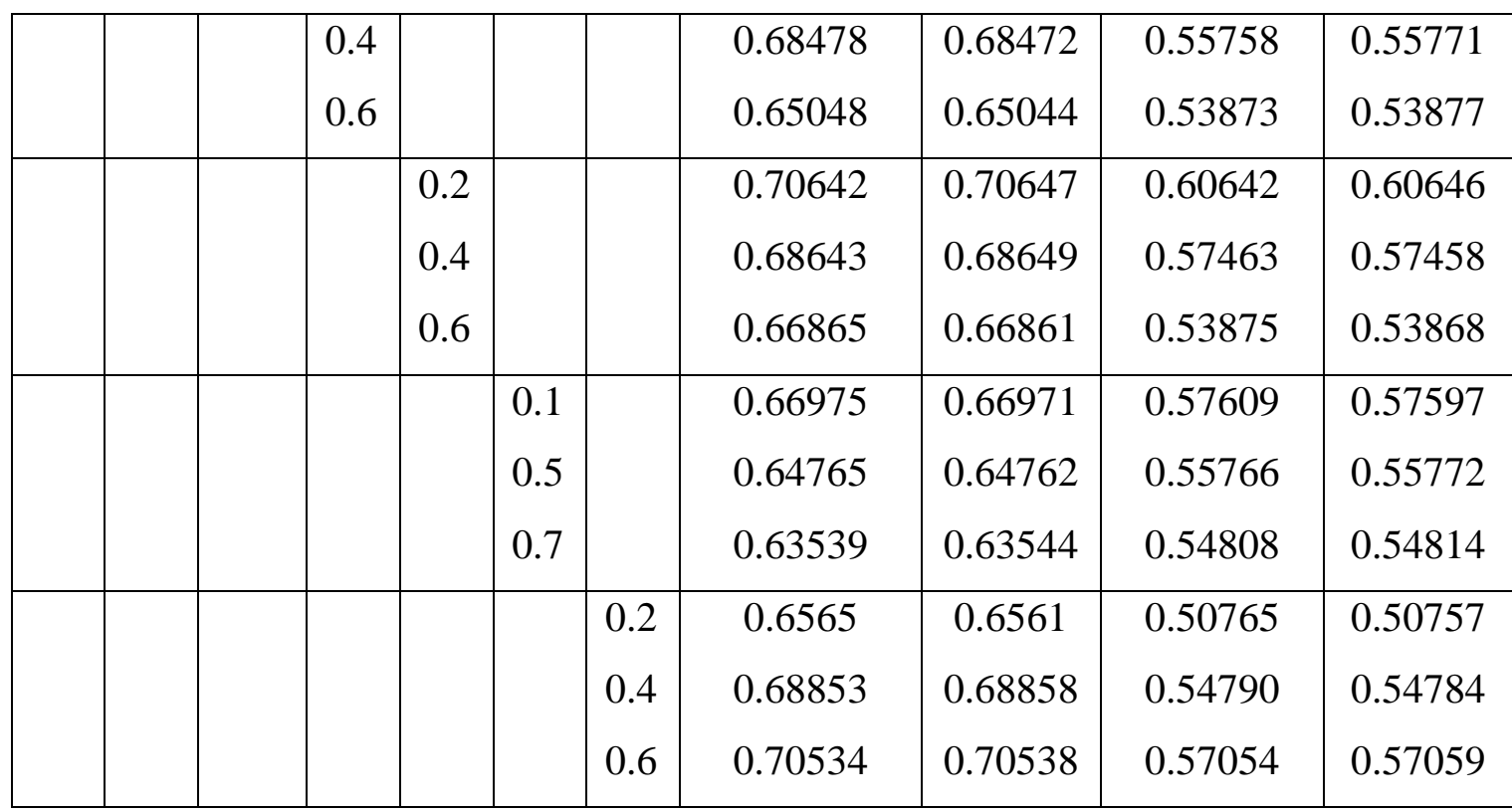

Novel correlation are reported for specified numerical values of parameters like $M, \delta, R, \operatorname{Pr}, E c, \lambda, m$ and $n$. The careful scrutiny of Table 1 shows that consistently higher skin friction values are computed with pseudoplastic fluids $(n=0.8)$ compared with dilatant fluids $(n=1.2)$, at any combination of the other 7 parameters. Similarly, Table 2 reveals that local Nusselt numbers are also consistently higher for pseudoplastic fluids $(n=0.8)$ compared with dilatant fluids $(n=1.2)$, at any combination of the other 7 parameters. These trends are due to the reduced viscosity effect in pseudoplastic (shear-thinning) magnetic polymers compared with dilatant (shear thickening) polymers. Primary skin friction is consistently decreased with greater generalized slip parameter, $\lambda$, for both pseudoplastic and dilatant polymers. Hydrodynamic slip therefore decelerates the primary flow. Maximum primary skin friction is therefore computed for the no-slip case $(\lambda=0)$ implying that neglection of slip in the model leads to an over-prediction in skin friction. However, an increase in mixed convection parameter, $\delta$ generates the opposite effect and enhances primary skin friction for both pseudoplastic and dilatant fluids. Increasing magnetic field parameter, $M$, clearly extensively slows down the primary flow (i.e. declines skin friction) for both power-law cases; however, it never induces flow reversal. The contrary behavior is induced with increasing Hall current parameter, $m$ i.e. strong flow acceleration is induced. The destruction in momentum due to the Lorentzian force is compensated with a boost in momentum in the secondary (cross) flow which results in an acceleration and a thinner primary momentum boundary layer. This effect has been computed by many other investigators including El Aziz [20] and Kamran et al. [22]. Table 2 shows that with leading variation in $\operatorname{Pr}$, which corresponds to a reduction in magnetic polymer thermal conductivity, induces a significant elevation transportation of heat from the boundary layer regime to the wall i.e. boosts local Nusselt number. Since thermal conductivity is lower, heat cannot conduct as efficiently in the body of the magnetic polymer and as such is drained to the boundary. This pattern is computed for both pseudoplastic $(n=0.8)$ and dilatant $(n=1.2)$ cases. A similar result has been reported by Mehta and Rao [14]. A consistent elevation in local Nusselt number is also observed with greater values of generalized slip parameter, $\lambda$. Evidently hydrodynamic slip at the sheet surface inhibits the transport of heat within the boundary layer and encourages heat migration to the wall. Conversely greater values of mixed convection parameter, $\delta$ serve to suppress the local Nusselt number since this parameter induces heating of the 
thermal boundary layer and a thicker structure. A marked depletion in local Nusselt number also accompanies an increase in magnetic parameter, $M$. The kinetic energy expended by the dragging the polymer against the action of the axial magnetic field is dissipated as heat. This energizes the boundary layer and elevates temperatures leading to a decrease in heat transfer from the wall to the fluid. With increasing radiation parameter, $R$, there is also a substantial suppression in local Nusselt number. Increasing radiative flux augments thermal diffusion and energizes the regime. Temperature and thermal boundary layer thickness are enhanced. However, this concurrently produces a decrease in thermal diffusion to the wall resulting in lower local Nusselt number magnitudes. As with variation in other parameters, both pseudoplastic and dilatant fluids respond in the same fashion to a change in a particular parameter i.e. they both increase or decrease. A significant decrease in local Nusselt number is also observed with an increase in Eckert number, $E c$. This parameter features in both the Joule dissipation, $+\operatorname{Pr} E c\left(M f^{\prime 2}\right)$ and viscous heating and terms, i.e. $+\operatorname{Pr} E c\left[1 / 2\left|f^{\prime \prime}\right|\right]^{n+1}$ in the energy conservation Eqn. (15). The former corresponds to the thermal energy dissipated via resistance of the magnetic field. The latter is the conversion of kinetic energy via internal friction in the magnetic polymer. Both are characterized by the Eckert number $E c=u_{w}^{2} / c_{p}\left(T_{w}-T_{\infty}\right)$ which quantifies the mechanical energy dissipated relative to the enthalpy difference across the boundary layer. Clearly significant heating is induced by both viscous and Joule dissipation which will thicken the thermal boundary layer and inhibit heat transfer to the wall. Local Nusselt numbers will therefore be reduced. These trends agree with many other studies e.g. Abdel-Wahed [33] and Babu and Narayana [34]. Indeed, this behavior is also confirmed in many standard engineering MHD reference books including Cramer and Pai [66], Hughes and Young [67] and Sutton and Shercliff [68]. An increase in Hall parameter, $m$, results in the opposite response to increasing magnetic field, $M$. It enhances local Nusselt number i.e. accentuates heat transfer to the wall and simultaneously decreases temperature field and thickness of thermal boundary layer in the magnetic polymer. Cross flow as mobilized by Hall current therefore produces excessive cooling in the polymer whereas stronger magnetic field generates heating.

\section{PRIMARY, SECONDARY VELOCITY, TEMPERATURE RESULTS AND DISCUSSION}

Although secondary skin friction was not considered in the previous section, here a detailed appraisal of the control parameters on primary and secondary velocity, in addition to temperature distributions is presented. The results are depicted in Figs. 2-14. Default values prescribed are as follows: $M=0.5, \delta=0.2, R=0.4, \operatorname{Pr}=0.5, E c=0.2$ and $\lambda=0.3$ the low Prandtl number of 0.5 is associated with liquid metal polymers (ECPs) which possess higher Prandtl numbers than pure liquid metals but much lower than aqueous solutions $[69,70]$. The momentum diffusivity is therefore half the thermal diffusivity. As in Tables 1, 2, here in all figures we present results for both cases of pseudoplastic $(n=0.8)$ and dilatant magnetic polymers $(n=1.2)$. 


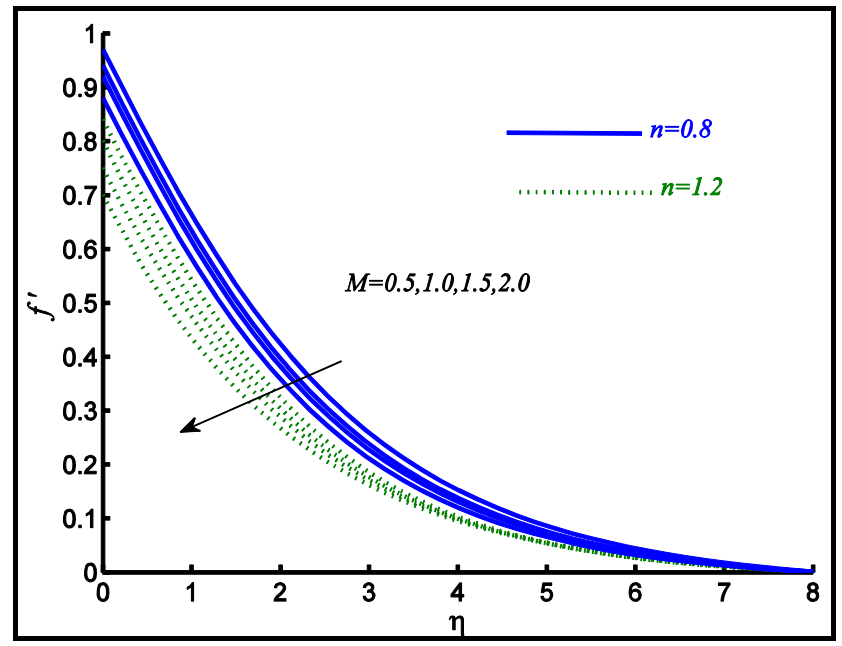

Fig.2: Effects of $M$ on $f^{\prime}$ with $m=0.2, \delta=0.2, R=0.4, \operatorname{Pr}=0.5, E c=0.2, \lambda=0.3$.

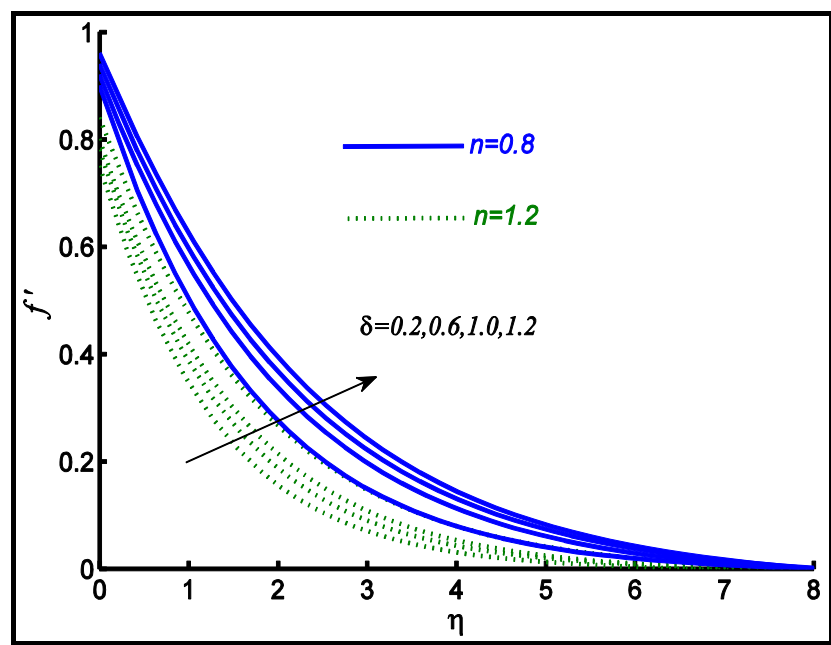

Fig.3: Effects of $\delta$ on $f^{\prime}$ with $M=0.2, m=0.2, R=0.4, \operatorname{Pr}=0.5, E c=0.2, \lambda=0.3$.

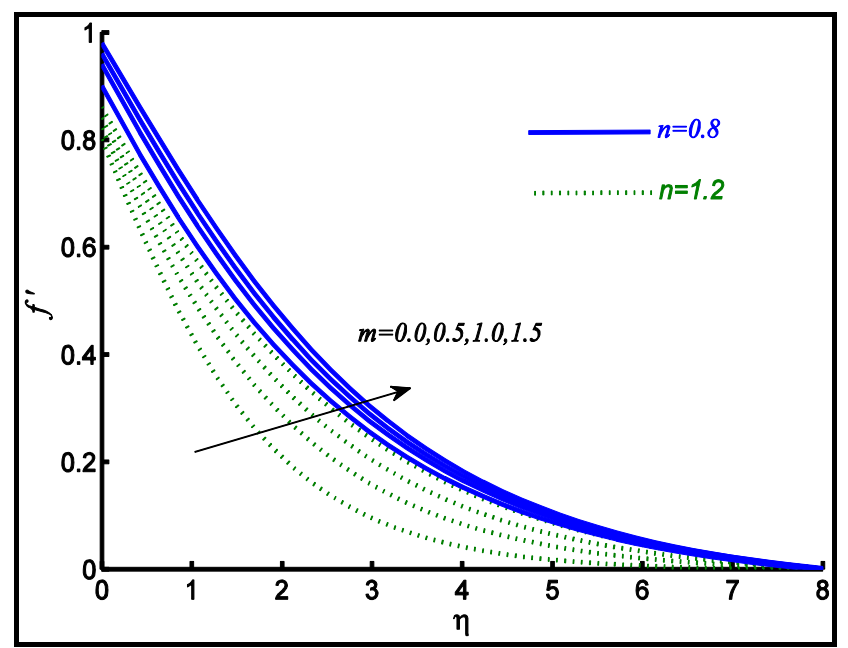

Fig.4: Effects of $m$ on $f^{\prime}$ with $M=0.5, \delta=0.2, R=0.4, \operatorname{Pr}=0.5, E c=0.2, \lambda=0.3$. 


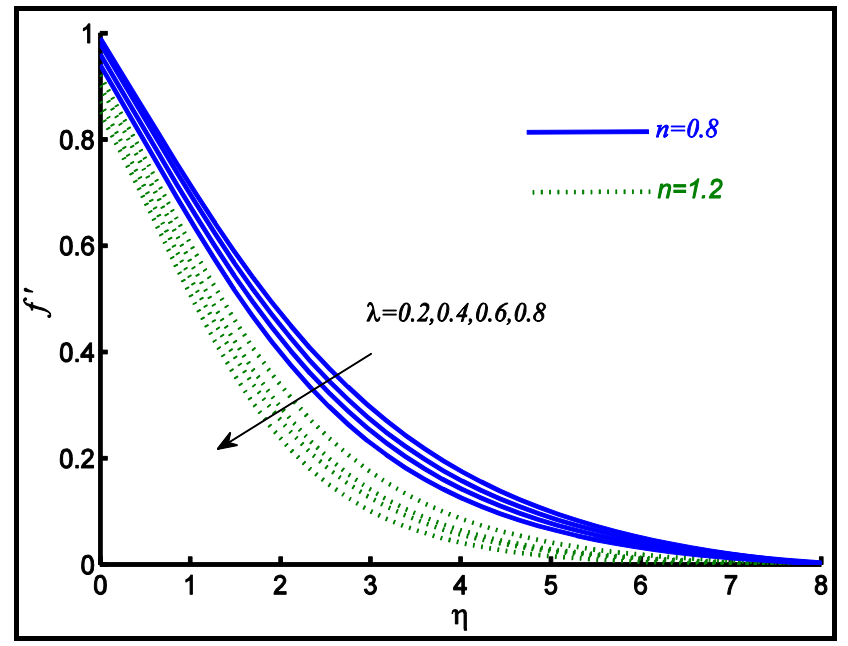

Fig.5: Effects of $\lambda$ on $f^{\prime} M=0.2, m=0.2, R=0.4, \operatorname{Pr}=0.5, E c=0.2, \delta=0.3$.

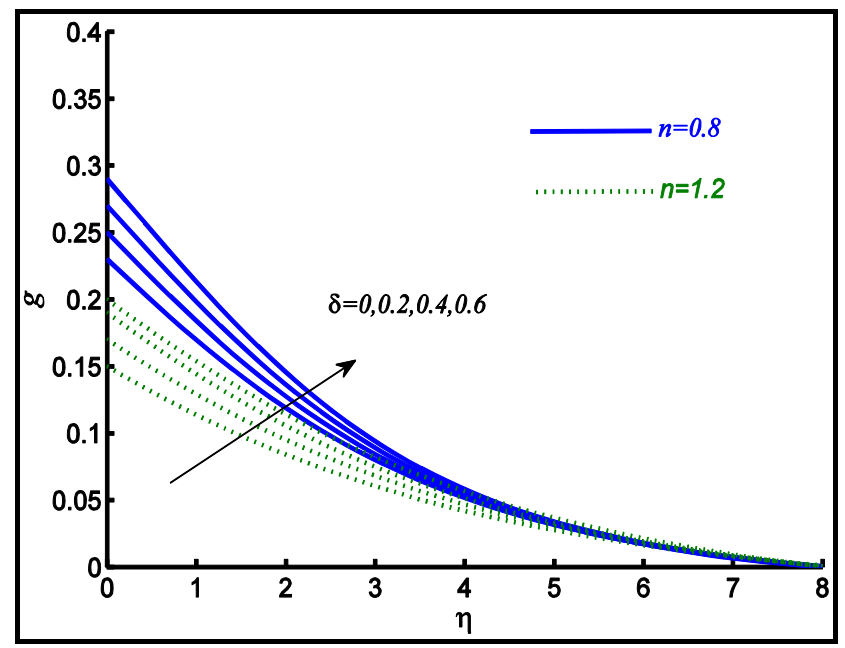

Fig.6: Effects of $\delta$ on $g M=0.2, m=0.2, R=0.4, \operatorname{Pr}=0.5, E c=0.2, \lambda=0.3$.

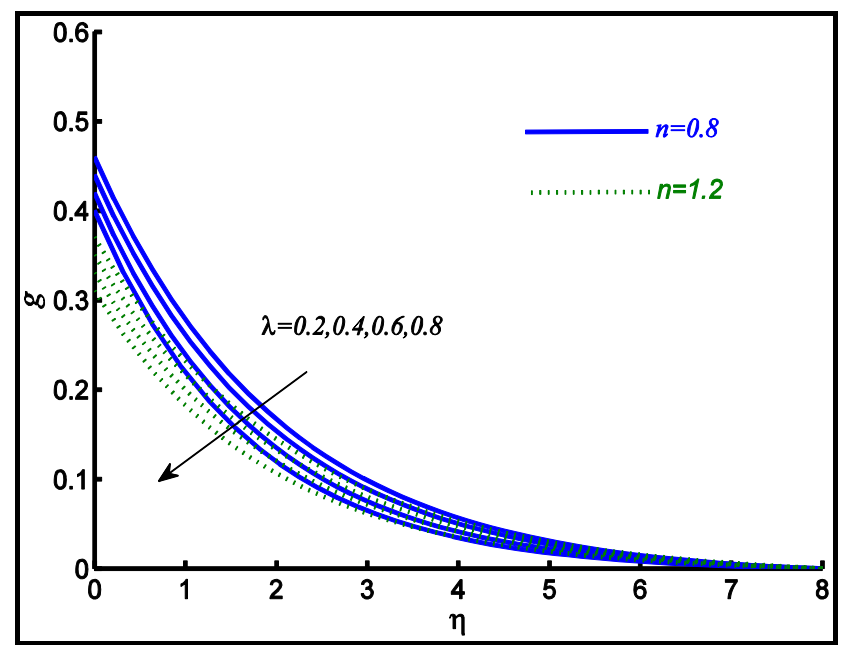

Fig.7: Effects of $\lambda$ on $g$ with $M=0.2, m=0.2, R=0.4, \operatorname{Pr}=0.5, E c=0.2, \delta=0.3$. 
16

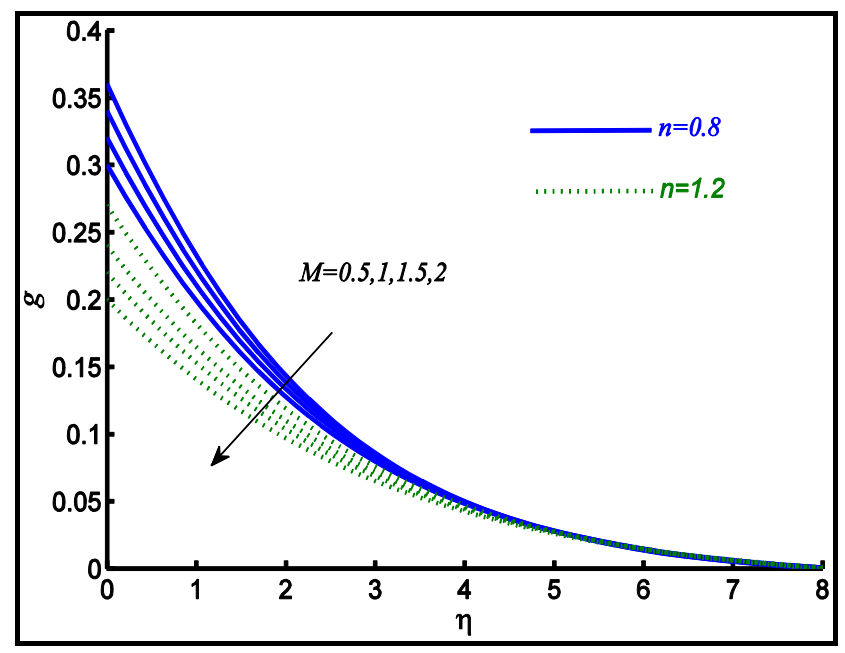

Fig.8: Effects of $M$ on $g \delta=0.3, m=0.2, R=0.4, \operatorname{Pr}=0.5, E c=0.2, \lambda=0.3$.

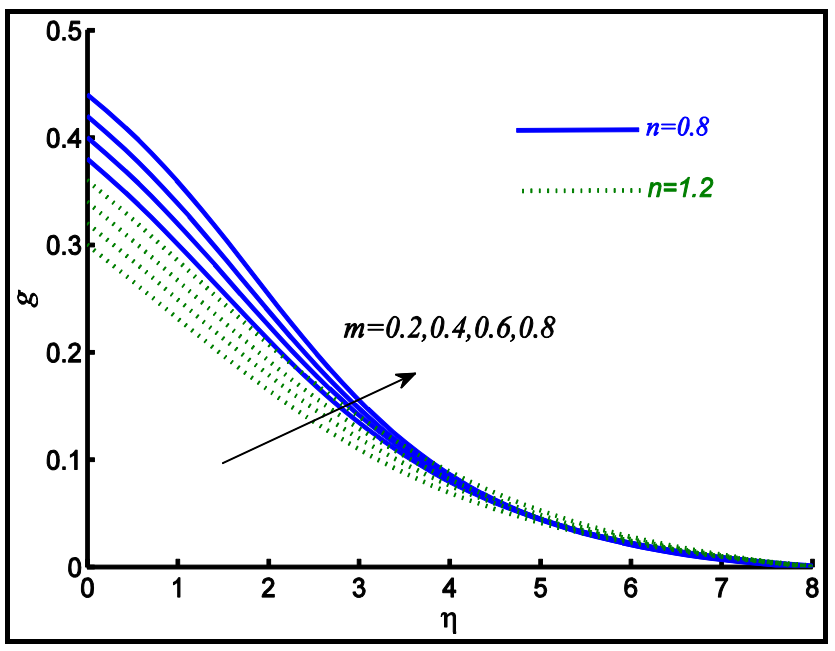

Fig.9: Effects of $m$ on $g M=0.2, \delta=0.3, R=0.4, \operatorname{Pr}=0.5, E c=0.2, \lambda=0.3$.

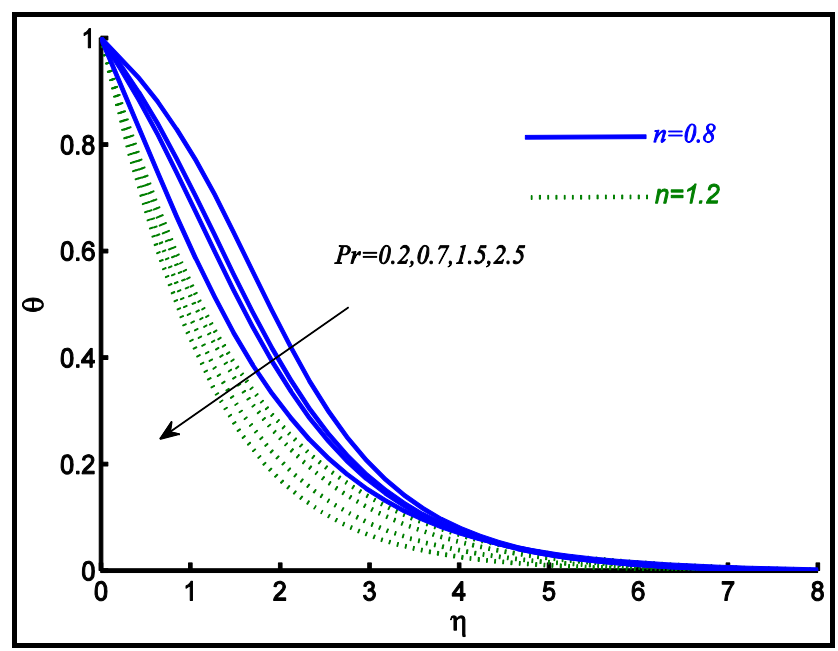

Fig.10: Effects of $\operatorname{Pr}$ on $\theta$ with $M=0.2, m=0.2, R=0.4, \delta=0.3, E c=0.2, \lambda=0.3$. 


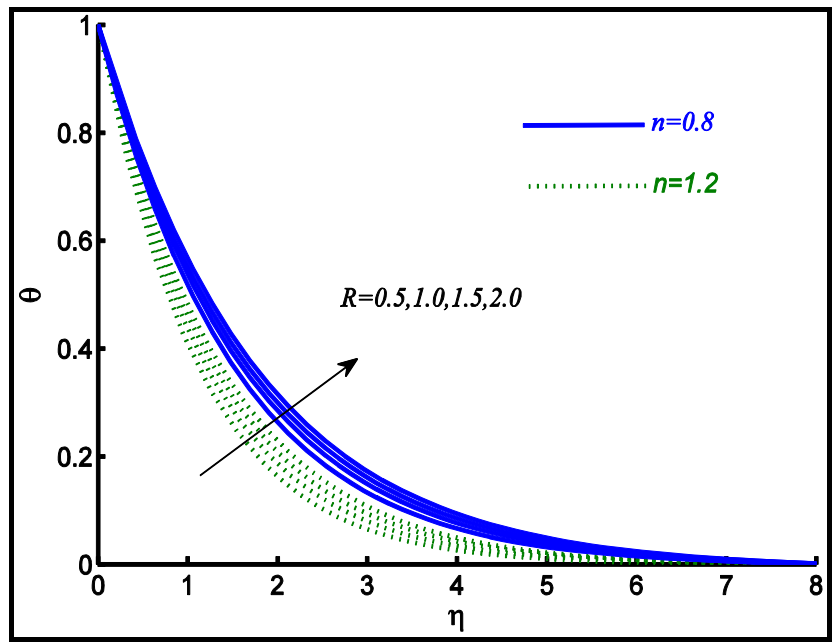

Fig.11: Effects of $R$ on $\theta$ with $M=0.2, m=0.2, \operatorname{Pr}=0.5, \delta=0.3, E c=0.2, \lambda=0.3$.

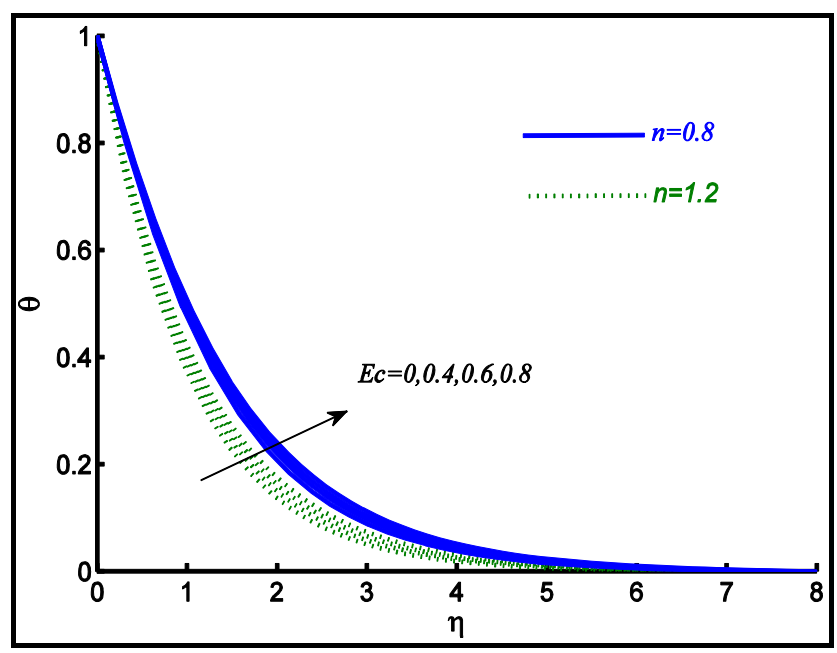

Fig.12: Effects of $E c$ on $\theta$ with $M=0.2, m=0.2, R=0.4, \delta=0.3, \operatorname{Pr}=0.5, \lambda=0.3$.

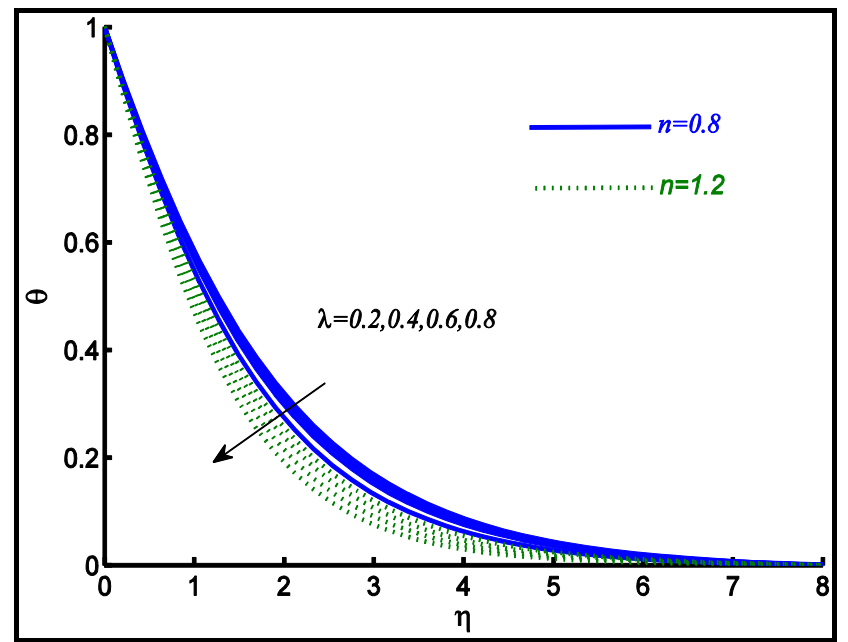

Fig.13: Effects of $\lambda$ on $\theta$ with $M=0.2, m=0.2, R=0.4, \delta=0.3, E c=0.2, \operatorname{Pr}=0.5$. 


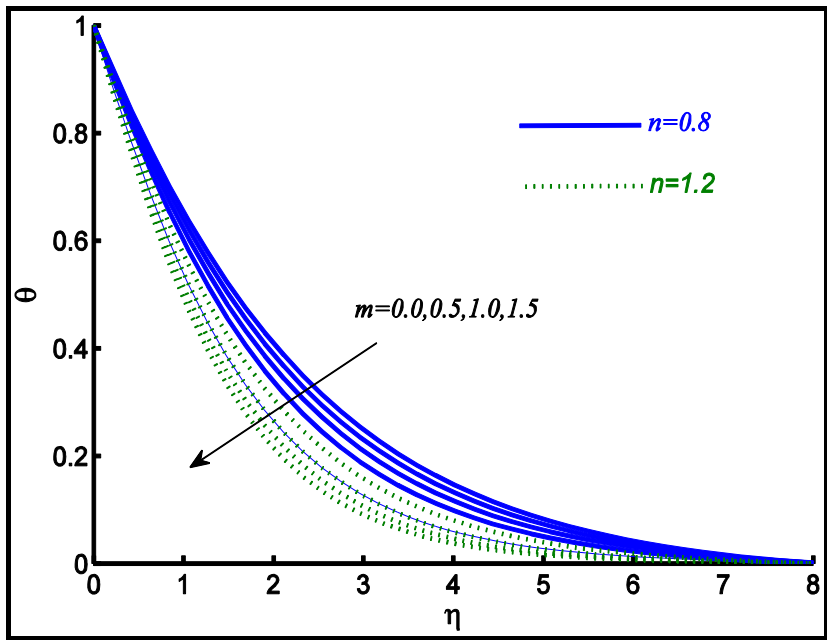

Fig.14: Effects of $m$ on $\theta$ with $M=0.2, \operatorname{Pr}=0.5, R=0.4, \delta=0.3, E c=0.2, \lambda=0.3$.

Fig. 2illustrates the impact of Hartmann number $M$ on primary velocity distribution $f^{\prime}(\eta)$. A declining pattern is observed for both cases from the wall to the free stream. However, the declining variation is more dominant for dilatants fluids. The Hartmann number is physically related to the Lorentz force which inhibits the flow and induces deceleration in both pseudoplastic and dilatant cases. It appears in the augmented magnetic body force term, $\left(M /\left(1+m^{2}\right)\right)\left(f^{\prime}+m g\right)$ in the primary momentum eqn. (13) which is coupled also to the secondary velocity field by virtue of the Hall parameter, $m$. Maximum primary velocity for either pseudoplastic or dilatant fluid cases clearly corresponds to the weakest magnetic field $(M=0.5)$ for which the primary momentum boundary layer thickness is minimized. The converse situation applies to the strongest magnetic field, $M=2$ for which primary boundary layer thickness is a maximum. Evidently increasing magnetic field significantly regulates the primary boundary layer behavior. Although retardation is successfully induced i.e. strong damping of the primary field, no flow reversal is computed indicating the boundary layer is attached and no separation arises.

Fig. 3. depicts the influence of mixed convection parameter, $\delta$ on primary velocity, $f^{\prime}$. An enhancement in velocity is observed since larger values of $\delta$ augment the thermal buoyancy force appearing in the primary momentum eqn. (13), viz $+\delta \theta$. Since mixed convection parameter is a function of local Grashof number (it equals $G r_{x} / R_{e}^{2}$ ) thermal buoyancy will significantly increase relative to viscous hydrodynamic force and this will decrease primary momentum boundary layer thickness. Once again higher primary velocity magnitudes are computed for the pseudoplastic case as compared with the dilatant case.

Fig. 4shows the evolution in primary velocity, $f^{\prime}(\eta)$ with variation in Hall parameter $m$. As noted earlier this parameter is connected to the magnetic body force term. Clearly increasng $\mathrm{m}$ values result in a notable enhancement in primary velocity, with a greater increase for the dilatant case over the same increment in Hall parameter. However overall the maximum primary velocity magnitudes are associated as before with the pseudoplastic case. The nature of the $-\left(M /\left(1+m^{2}\right)\right)\left(f^{\prime}+m g\right)$ body force term is that the secondary flow $(g)$ increasingly contributes to momentum development in the primary flow field with progessive increase in $m$. The cross flow effect therefore assists primary velocity development and manifests in 
significant acceleration throughout the boundary layer. In the absence of Hall current $(m=0)$, minimal primary velocity is computed for both pseudoplastic and dilatant cases. The implicaiton is that negelction of this important parameter consdierably under-predicts the actual primary velocity leading to erroneous results in magnetic polymer processing simulations. It is also noteworthy that no cross-over of profiles is computed at any location transverse to the wall i.e. the correct behaviour is reflected in all values of transverse coordinate, and asymptotically smooth convergence into the free stream is achieved with the MATLAB code. Similar trends have been reported earlier for other non-Newtonian fluids e.g. micropolar [22], viscoplastic [23] and and also Newtonian liquids [25]. The overall effect of Hall current would therefore appear to be largely independent of the rheological model adopted for the magnetic polymer although significantly different velocity magnitudes will arise due to the different shear stress-strain characteristics associated with these different models.

Fig. 5visualizes the primary velocity distribution, $f^{\prime}(\eta)$ response to a change in generalized hydrodynamic slip parameter $\lambda$. It is apparent that primary velocity is substantially depleted with larger values of $\lambda$.This parameter features in the wall boundary condition, $f^{\prime}(0)=1+\lambda\left|f^{\prime \prime}(0)\right|^{n-1} f^{\prime \prime}(0)$, in eqn. (16). The presence of slip is therefore inhibitive to momentum diffusion and results in a thicker primary momentum boundary layer. As anticipated, higher primary velocity magnitudes are achieved with the pseudoplastic fluid compared with dilatant fluid owing to much higher viscosity in the latter.

Fig. 6 presents the secondary (cross) flow velocity profiles $(g)$ versus transverse coordinate with different values of mixed convection parameter, $\delta$. Relative to the primary velocity, significantly lower magnitudes of secondary velocity are observed, in particular at the wall (where there is also a greater spread of magnitudes for the different profiles over the same range of power-law index, $\mathrm{n}$, and mixed convection parameter, $\delta$, values). As with primary velocity, a strong increase in secondary flow is induced with greater thermal buoyancy effect (higher $\delta$ values). Although $\delta$ does not feature in the secondary momentum eqn. (14), the strong coupling terms i.e. $\left(\frac{2 n-1}{n+1}\right) f g^{\prime},+\frac{M}{1+m^{2}}\left(m f^{\prime}-g\right),-f^{\prime} g$ result in the primary field strongly affecting the secondary field. Secondary momentum boundary layer thickness is considerably reduced with greater mixed convection parameter. Again, smooth convergence of profiles into the free stream vanishing value is achieved with the MATLAB solutions. The later profile of $g$ due to specified values of slip parameter $\lambda$ is depicted in Fig. 7. As with the primary field topologies, there is a significant retardation in secondary flow with greater slip effect, although the wall magnitudes are consistently lower than the primary velocity ones. Pseudoplastic fluids achieve higher secondary velocity magnitudes at any slip parameter relative to dilatant fluids. Maximum secondary flow acceleration therefore corresponds to weak slip $(\lambda=0.2)$ and maximum secondary flow deceleration to strongest $\operatorname{slip}(\lambda=0.8)$. Evidently the inclusion of wall slip effect in the magnetic polymer stretching model predicts secondary velocity values which are much lower than would be computed for the classical no slip case. The slip model therefore is more realistic and conservative for practical materials processing operations flow analysis and predicts a thicker secondary boundary layer.

Fig. 8 displays the secondary velocity profiles for various magnetic parameter $(M)$ values. Strong secondary flow deceleration is caused by increasing magnetic field strength. 
Effectively in the stretching flow regime, both primary and secondary components are retarded by the axial magnetic field ( $y$-direction) which is applied normal to the $x-z$ plane and generates mutually perpendicular inhibiting Lorentz forces in both the primary and secondary directions. This also results in an increase in secondary boundary layer thickness.

Fig 9. illustrates the secondary velocity distributions with Hall current parameter, $m$. The Hall current-modified magnetic drag force term, $+\left(M /\left(1+m^{2}\right)\right)\left(m f^{\prime}-g\right)$ in Eqn. (14) results in an effective negative term for the secondary velocity component i.e. $-\left(M /\left(1+m^{2}\right)\right)(m g)$ which has a similar effect to the corresponding term in the primary momentum eqn. (13) i.e. $-\left(M /\left(1+m^{2}\right)\right)(m g)$. However the primary velocity component in each is different- in eqn. (13) it is negative i.e. $-\left(M /\left(1+m^{2}\right)\right) f^{\prime}$ whereas in eqn. (14) it is positive i.e. $+\left(M /\left(1+m^{2}\right)\right) m f^{\prime}$. The latter is found to contribute significantly to assisting secondary momentum development i.e. accelerates the secondary flow and as noted before greater acceleration corresponds to pseudoplastic fluids comapred with dilatant fluids (the rheological index $\mathrm{n}$ features in multiple terms in both the primary and secondary momentum equations).

Figs. 10-14visualize the temperature distribution $\theta$ for variation in Prandtl number $\operatorname{Pr}$, radiation parameter $R$, Eckert number $E c_{z}$ wall slip parameter $\lambda$ and Hall parameter $m$, respectively. Increasing Prandtl number clearly suppresses temperatures throughout the magnetic polymer regime. Higher temperatures are produced for pseudoplastic rather than dialatant fluids. Prandtl number is inversely proportional to thermal conductivity for fixed values of the dynamic viscosity and specific heat capacity. Higher Prandtl number implies lower thermal conductivity of the magnetic polymer and vice versa. Thermal diffusivity exceeds momentum diffusivity for $\operatorname{Pr}<1$ and is less than momentum diffusivity it for $\operatorname{Pr}>1$; they are equal only when $\operatorname{Pr}=1$ for which thermal and momentum boundary layer thicknesses are the same in the regime. Lower Prandtl numbers therefore result in heating of the regime and higher values induce cooling i.e. decrease in thermal boundary layer thickness. The results concur with many other studies on thermofluid magnetic flows including Babu and Narayan [35].Fig. 11 displays the impact of thermal radiative heat transfer parameter, $R$, on the temperature evolution $(\theta)$ in the boundary layer regime. Featured solely in eqn. (15) since a separate equation is not required with the Rosseland flux model, as with other flux models (e.g. Schuster-Schwartzchild 2-flux model), $R=4 \sigma^{*} T_{\infty}^{3} / k^{*}$ expresses the relative contribution of thermal radiative transfer to thermal conductive heat transfer. When $R=0$ radiative effects are negated and when $R=1$ they are equivalent to conduction. Distinct enhancment in temperatures is caused with greater $R$ values since the regime is energized with radiative flux. Thermal boundary layer thickness is also accentuated for both pseudoplastic and dilatant fluids, although thicker thermal boundary layers are produced for shear-thinning polymers (pseudoplastic). Aagin it is pertinent to note that with radiative contribution neglected, temperatures are under-predicted in magnetic polymer flow simulations. The thermal diffusion term in eqn. (15) is significantly modified with the inclusion of radiative flux effect i.e. $(1+(4 R / 3)) \theta^{\prime \prime}$. Of course the present computations are limited to optically thick polymers. More refined insight into the variation of temperatures with optical thickness and refractive index requires more sophisticated flux models, which 
are presently under investigation.Fig. 12 visualizes the temperature distribution $(\theta)$ with Eckert number, $E c$, As noted earlier, Ec is featured in both viscous heating and Joule dissipation (Ohmic heating) terms in the energy eqn. (15), viz, $+\operatorname{Pr} E c\left(M f^{\prime 2}\right)$ and $+\operatorname{Pr} E c\left((1 / 2)\left|f^{\prime \prime}\right|^{n+1}\right)$, respectively. Since these terms have higher degree they exert a strong influence on thermal diffusion in the regime. They signifiy the conversion of electrical energy to heat via magnetic resistance and mechanical energy to heat via internal fluid friction, respectively.Temperatures are strongly boosted with $E c$ therefore and thermal boundary layer thickness is elevated; again the enhancment is greater for pseudoplastic rather than dilatant polymers (rheological power-index, $n$, appears inseveral terms in the energy eqn. (15), viz, $\operatorname{Pr}(2 n-1 / n+1) f \theta^{\prime}$ and the viscous heating term, $+(1 / 2)\left|f^{\prime \prime}\right|^{n+1}$. Again it is noteworthy that an absence of these terms in many thermomagnetic materials flow simulation will lead to a significant under-prediction in temperatures (and a simultaneous over-prediction in local Nusselt numbers). These issues have been emphasized in a number of other studies including El-Amin [37] who has also computed similar results, albeit for Newtonian fluids in the absence of thermal buoyancy effect (forced convection).Fig. 13displays the evolution in temperatures $(\theta)$ with hydrodynamic wall slip parameter, $\lambda \mathrm{A}$ strong suppression in temperatures is generated with greater $\lambda$ values, although again pseudoplastic polymers attain higher magnitudes than diltant polymers. Thermal boundary layer thickness is therefore reduced susbtantially with greatre wall slip. As elaborated earlier, the exclusion of an appropriate momentum wall slip boundary condition would therefore markdely over-predict actual temperatures in the regime. The classical noslip condition adopted in numerous other works is therefore demonstrably inappropriate. Hatzikiriakos [51] has indicated at length that the slip velocity of molten polymers is a complex function and will inevitably depend on a multitude of different factors including wall shear and normal stresses, wall temperature, in addition to molecular characteristics of polymers (molecular weight and distribution). Further studies are therefore warranted with possible more elegant slip models to explore in more detail the exact modification to the momentum and thermal boundary layer structures induced by polymeric wall slip and these are also under consideration by the authors.Finally Fig. 14 shows the response in temperature distribution to a change in the Hall current parameter, $m$. Although absent in the thermal boundary layer eqn. (15), the effect of Hall current is imparted to the temperature field via multiple coupled terms in this equation in addition to those appearing in the primary and secondary momenta equations. These include the terms, $\operatorname{Pr}(2 n-1 / n+1) f \theta^{\prime},-2 \operatorname{Pr} f^{\prime} \theta$ coupling the energy eqn. (15) to the primary momentum eqn. (13), and the thermal buoyancy force coupling term in eqn. (13), viz $+\delta \theta$. The Hall current terms in eqns. (13) and (14) also couple the two velocity fields to each other, and in turn this then impacts on the temperature field via the primary velocity coupling terms explained earlier. The overall effect is that temperatures are depleted with stronger Hall current effect and thermal boundary layer thickness is therefore also reduced. Maximum temperatures are produced in the absence of Hall current $(m=0)$ for which thermal boundary layers are thickest. The implication again is that negation of Hall current effect in magnetic polymer flows not only removes the crossflow phenomenon (secondary velocity field) but also influences temperature distribution in the polymer. As observed in all other plots, pseudoplastic polymers are found to achieve higher temperatures (thicker thermal boundary layers) than dilatant polymers. 


\section{CONCLUDING REMARKS}

A theoretical model for radiative mixed convective slip flow of power law non-Newtonian magnetic polymer from a convectively heated uni-directionally exponentially stretching surface under a transverse static magnetic field has been developed, as a simulation of magnetic polymer (ECP) and liquid metal polymer fabrication processes. The novel features of the model are the inclusion of Hall current, Joule heating (Ohmic electromagnetic dissipation) and viscous dissipation all of which are known to characterize actual magnetic polymeric fabrication systems. An algebraic flux model has been deployed to model radiative heat transfer contributions. Hall current induces across flow necessitating the inclusion of both primary and secondary momentum conservation equations. Local similarity transformations have been implemented to render the coupled, nonlinear multi-degree ordinary differential boundary value problem as dimensionless. With physically realistic data employed, numerical solutions have been developed using MATLAB shooting quadrature and verified with a generalized differential quadrature (GDQ) technique. The key findings of the present simulations may be summarized as follows:

Increasing mixed convection parameter and Hall current parameter both accelerate the primary and secondary flows and decrease hydrodynamic boundary layer thicknesses.

$>$ Greater primary and secondary velocity and also temperature are consistently computed for pseudoplastic fluids as compared with dilatant fluids.

$>$ Secondary velocity is decreased substantially with increasing hydrodynamic wall slip parameter and magnetic body force number (Hartmann number).

$>$ Temperatures are elevated markedly (as are thermal boundary layer thicknesses) with increasing radiation parameter and Eckert number (i.e. greater viscous and Joule heating).

$>$ Temperatures are suppressed (and thermal boundary layer thicknesses reduced) with greater wall slip and Hall current parameter.

$>$ Primary wall shear stress is depleted with increasing magnetic field parameter (Hartmann number) and wall slip parameter i.e. strong deceleration is induced in the primary flow.

$>$ An increase in Hall parameter, strongly elevates local Nusselt number i.e. accentuates heat transfer to the wall.

$>$ Cross (secondary) flow as mobilized by Hall current produces excessive cooling in the electroconductive polymer whereas stronger magnetic field generates heating.

The present study has been restricted to a simple flux approximation for radiative heat transfer. Future studies may consider alternative models e.g. Traugott P1 differential approximation, and this will permit greater scrutiny of radiative properties of the magnetic polymer. Furthermore, more complex magnetic phenomena may also be addressed in future studies including ferro-magnetics, magnetic leakage, relaxation etc.

\section{ACKNOWLEDGMENTS}

The authors are grateful to the second reviewer for his/her interesting comments which have served to improve the present work.

\section{REFERENCES}

[1] J.H. Lupinski,K.D. Kopple, Electroconductive polymers,Science.20 (1964)1038-1039.

[2] D.G. Pijanowska, K. Agnieszka,W. Torbicz,Electroconductive polymers in (bio) chemical sensors, Biocybernetics and Biomed. Eng.31 (2011)43-57. 
[3] A. Guiseppi-Elie, Electroconductive hydrogels: synthesis, characterization and biomedical applications, Biomaterials. 31(2010) 2701-2716.

[4] A. Ronen, S.I. Walker,D. Jassby, Electroconductive and electro-responsive membranes for water treatment, Rev. Chem. Eng.32(5) (2016) 533-550.

[5] M. Ates,A review study of (bio)sensor systems based on conducting polymers, Mat. Sci. Eng: C.33 (2013) 1853-1859.

[6] L.M. Lira, S.I.C. de Torresi, Conducting polymer-hydrogel composites for electrochemical release devices: Synthesis and characterization of semi-interpenetrating polyaniline-polyacrylamide networks, Electrochem. Commun.7 (2005) 717-723.

[7] T. Julie, O. Hugo, S. Olivier,L. Sébastien, Magnetic responsive polymer composite materials,Chem. Soc. Rev: Royal Soc. Chemistry.42(17) 2013 7099-7116.

[8] J. Prakash, E.P. Siva, D. Tripathi, S. Kuharat,O. Anwar Bég, Peristaltic pumping of magnetic nanofluids with thermal radiation and temperature-dependent viscosity effects: modelling a solar magneto-biomimetic nanopump, Renewable Energy 133 (2019) 1308-1326.

[9] J.H. Lee, Q. Lu, J.Y. Lee, H.J. Choi, Polymer-magnetic composite particles of $\mathrm{Fe}_{3} \mathrm{O}_{4} / \mathrm{Poly}(\mathrm{o}$-anisidine) and their suspension characteristics under applied magnetic fields, Polymers. 11(2) (2019) 219.https://doi.org/10.3390/polym11020219.

[10] MD. Shamshuddin, M. Ferdows, M. Rezwan,O. Anwar Bég,A. Kadir, Ferromagnetic and non-magnetic nanoparticles in nanofluid flow from a stretching cylinder with magnetic induction: spectral relaxation solution,Proc. Int. Conf. Numerical Heat Transfer and Fluid Flow (NHTFF-2020), NIT Warangal, India - Jan 17-19 (2020).

[11] P.S. Lawrence, B.N. Rao, Heat transfer in the MHD flow of a viscoelastic fluid over a stretching sheet, ZAMM - J. Appl. Math. Mech. / Zeitschrift für Angewandte Mathematik und Mechanik77(4) (1997)317-319.

[12] R.S.R. Gorla, V. Dakappagari,I. Pop, Three-dimensional flow of a power-law fluid due to a stretching flat surface, ZAMM-J. Appl. Math. Mech. / Zeitschrift für Angewandte Mathematik und Mechanik. 75(5) (1995) 20-30.

[13] H.I. Andersson,V. Kumaran, On sheet-driven motion of power-law fluids, Int. J. NonLinear Mech. 41 (2006) 1228-1234.

[14] K.N. Mehta, K.N. Rao, Buoyancy-induced flow of non-Newtonian fluids over a nonisothermal horizontal plate embedded in a porous medium, Int. J. Eng. Sci. 32 (1994) 521-525.

[15] R.Y. Jumah, A.S. Mujumdar, Free convection heat and mass transfer of non-Newtonian power law fluids with yield stress from a vertical flat plate in saturated porous media, Int. Commun. Heat and Mass Transf. 27 (2000) 485-494.

[16] P.D. Ariel, On the flow of power law fluid over a stretching sheet-techniques and solutions, Acta Mech.156 (1) (2002) 13-27.

[17] H.I. Andersson, K.H. Bech, Dandapat BS, Magnetohydrodynamic flow of a power-law fluid over a stretching sheet, Int. J. Non-Linear Mech.27 (1992) 929-936.

[18] M. Aneja, S. Sapna, S. Kuharat,O. Anwar Bég,Computation of electroconductive gyrotactic bioconvection under non-uniform magnetic field: Simulation of smart bionanopolymer coatings for solar energy,Int. J. Modern Physics B. 33 (2020) Article ID:2050028.https://doi.org/10.1142/S0217979220500289.

[19] M.K. Chaube, D. Tripathi, O. Anwar Bég, S. Shashi, V.S. Pandey, Peristaltic creeping flow of power law physiological fluids through a non-uniform channel with slip effect, Appl. Bionics and Biomech. 2015 (2015) Article ID:152802. https://doi.org/10.1155/152802. 
[20] M. Abd El-Aziz, Effects of Hall current on the flow and heat transfer of a nanofluid over a stretching sheet with partial slip, Int. J. Modern Physics C.24 (2013) Article ID:1350044. https://doi.org/10.1142?s0129183113500447

[21] K. Ramesh, D. Tripathi, O. Anwar Bég, A. Kadir, Slip and Hall current effects on viscoelastic fluid-particle suspension flow in a peristaltic hydromagnetic blood micropump, Ir. J. Sci. Tech.: Transactions of Mech. Eng. (2018). https://doi.org/10.1007/s40997-018-0230-5.

[22] M. Kamran, B. Wiwatanapataphee,K. Varavelu, Hall current, Newtonian heating and second-order slip effects on convective magneto-micropolar fluid flow over a sheet,Int. J. Modern Physics C. 29 (9) (2018) Article ID:1850090. https://doi.org/10.1142/S0129183118500900

[23] M.M. Bhatti, C.M. Khalique, O. Anwar Bég,A. Kadir, Differential transform solution for Hall and Ion slip effects on radiative-convective viscoplastic Casson flow from a stretching sheet with convective heating, Heat Transfer-Asian Res. 49(2) (2019) 872888.

[24] O. Anwar Bég, S. Rawat, J. Zueco, L. Osmond, R.S.R. Gorla, Finite element and network electrical simulation of rotating magnetofluid flow in nonlinear porous media with inclined magnetic field and Hall currents, Theoret. Appl. Mech.41 (1) (2014)1-35.

[25] S. Siva Reddy, O. Anwar Bég, P. Modugula, A. Kadir, Computation of transient radiative reactive thermo-solutal magneto-hydrodynamic convection in inclined MHD Hall generator flow with dissipation and cross diffusion, Comput. Therm. Sci.11(6) (2019) 541-563.

[26] O. Anwar Bég, M. Ferdows, M.E. Karim, M.M. Hasan, T.A. Bég, MD. Shamshuddin MD, Kadir A, Computation of non-isothermal thermo-convective micropolar fluid dynamics in a Hall MHD generator system with non-linear distending wall, Int. JAppl. Comput. Math.6 (2020) 1-44.

[27] M. Biesuz, M. Cipriani, V.M. Sglavo, G.D. Soraru, Electrode-dependent Joule heating in soda lime silicate glass during flash processes, Scripta Materialia.182 (2020) 94-98.

[28] B. Bhattacharyya, Electrochemical Machining, in Electrochemical Micromachining for Nanofabrication, MEMS and Nanotechnology, USA, 2015.

[29] L. Ahmad, A. Munir, M. Khan, Locally non-similar and thermally radiative Sisko fluid flow with magnetic and Joule heating effects, J. Magn. Magn. Mat.4871 (2019) Article ID:165284. https://doi.org/10.1016/j.jmmm.2019.165284

[30] O. Anwar Bég, J. Zueco,H.S. Takhar, Unsteady magnetohydrodynamic HartmannCouette flow and heat transfer in a Darcian channel with Hall current, ionslip, viscous and Joule heating effects: Network numerical solutions, Commun. Nonlinear Sci. Numer. Simult. 14 (2009) 1082-1097.

[31] K. Haldar,D.C. Lagoudas, Dynamic magnetic shape memory alloys responses: Eddy current effect and Joule heating, J. Magn. Magn. Mat.4651 (2018) 278-289.

[32] D. Tripathi, S. Ashish, O. Anwar Bég, Electrothermal transport of nanofluids via peristaltic pumping in a finite micro-channel: effects of Joule heating and HelmholtzSmoluchowski velocity, Int, J. Heat and Mass Transf. 111 (2017) 138-149.

[33] M.S. Abdel-Wahed, Rotating ferro-nanofluid over stretching plate under the effect of Hall current and joule heating, J. Magn. Magn. Mat.429 (2017) 287-293.

[34] MD. Shamshuddin, S.R. Mishra, O. Anwar Bég,A. Kadir, Viscous dissipation and Joule heating effects in non-Fourier MHD squeezing flow, heat and mass transfer between Riga plates with thermal radiation: variational parameter method solutions, Arabian J. Sci. Eng. 44(9) (2019) 8053-8066. 
[35] D.H. Babu,P.V.S. Narayana, Joule heating effects on MHD mixed convection of a Jeffrey fluid over a stretching sheet with power law heat flux: A numerical study, J. Magn. Magn. Mat.41215 (2016) 185-193.

[36] MD. Shamshuddin, S.R. Mishra, O. Anwar Bég, A. Kadir, Unsteady reactive magnetic radiative micropolar flow, heat and mass transfer from an inclined plate with Joule heating: a model for magnetic polymer processing,Proc. IMechE- Part C. - Mech. Eng. Sci.223 (4) (2019) 1-8.

[37] M.F. El-Amin, Combined effect of viscous dissipation and Joule heating on MHD forced convection over a non-isothermal horizontal cylinder embedded in a fluid saturated porous medium, J. Magn. Magn. Mat.263 (2003) 337-343.

[38] R.B. Mansour,R. Viskanta, Radiative and convective heat transfer for materials processing.Proceedings of the First Conference on Transport Phenomena in Processing, (S.I. Guceri, Editor), Technomic Publishing Co., Lancaster, PA, USA, 1992; pp. 693713.

[39] J.C. Rozzi, F.P. Incropera, Y.C. Shin, Transient three-dimensional heat transfer model for the laser assisted machining of ceramic materials. Proceedings of the ASME Heat Transfer Division,(Zumbrunnen, D. A., Carmchi, M., Mahajan, R. L., Editors), ASME New York, 351 (1997) 75-85.

[40] K.H. Lee,R. Viskanta, Transient conductive-radiative cooling of an optical quality glass disk,Int. J. Heat and Mass Transf.41 (1998) 2083-2096.

[41] S.R. Mishra, MD. Shamshuddin, O. Anwar Bég,A. Kadir, Adomain computation of radiative-convective bi-directional stretching flow of a magnetic non-Newtonian fluid in porous media with homogeneous-heterogeneous reactions, Int. J. Modern Physics B.(2020)Article ID: JPB20076408.

[42] M. Imtiaz,T. Hayat, Flow of magneto nanofluid by a radiative exponentially stretching surface with dissipation effect,Adv. Powder Tech. 27 (5) (2016) 2214-2222.

[43] O. Anwar Bég, M.J. Uddin, M.M. Rashidi,N. Kavyani, Double-diffusive radiative magnetic mixed convective slip flow with Biot and Richardson number effects, J. Eng. Thermophys.23(2) (2014) 79-97.

[44] N. Khan, I. Riaz, M.S. Hashmi, S.A. Musmar, S.U. Khan, Z. Abdelmalek,I. Tlili, Aspects of chemical entropy generation in flow of Casson nanofluid between radiative stretching disks,Entropy.22 (2020) Article ID:495.https://doi.org/10.3390/e22050495

[45] R. Cortell, Suction, viscous heating and thermal radiation effects on the flow and heat transfer of a power-law fluid past an infinite porous plate, Proc. IChmeE, Chem. Eng. Res. Design. 89 (2011) 85-93.

[46] M.J. Uddin, O. Anwar Bég,A.I.M. Ismail, Radiative-convective nanofluid flow from a stretching/shrinking sheet with slip effects, AIAA J. Thermophys. Heat Transf., 29(3) (2015) 513-523.

[47] O. Anwar Bég, M. Ferdows, T.A. Bég, T. Ahmed, M. Wahiduzzaman, M.M. Alam, Radiative optically-dense magnetized transient reactive transport phenomena with cross diffusion and dissipation effects: numerical simulations, J. Taiwan Inst. Chem. Eng.66 (2016) 12-26.

[48] M.J. Uddin, O. Anwar Bég, M.N. Uddin, Energy conversion under conjugate conduction, magneto-convection, diffusion and nonlinear radiation over a non-linearly stretching sheet with slip and multiple convective boundary conditions,Energy.115 (2016) 1119-1129.

[49] J.V. Ramana Murthy, J. Srinivas, O. Anwar Bég, Entropy generation analysis of radiative heat transfer effects on channel flow of two immiscible couple stress fluids,J. Braz. Soc. Mech. Sci. Eng., 39 (2017) 2191-2202. 
[50] M. Denn, Extrusion instabilities and wall slip, Annual Rev. Fluid Mech. 33 (2001) 265287.

[51] S.G. Hatzikiriakos, Wall slip of molten polymers, Progress in Polymer Sci. 37 (4) (2012) 624-643.

[52] O. Anwar Bég, J. Zueco, L.M. López-Ochoa, Network numerical analysis of opticallythick hydromagnetic slip flow from a porous spinning disk with radiation flux, variable thermophysical properties and surface injection effects, Chem. Eng. Commun.198 (3) (2011) 360-384.

[53] M. Abd El-Aziz,A.A. Afify, Influence of slip velocity and induced magnetic field on MHD stagnation-point flow and heat transfer of Casson fluid over a stretching sheet, Math. Prob. Eng.(2018) Article ID 9402836.https://doi.org/10.1155/2018/9402836

[54] B. Sahoo,Effects of slip on sheet-driven flow and heat transfer of a non-Newtonian fluid past a stretching sheet, Comput\& Math. Applic.61 (2011) 1442-1456.

[55] C.Y. Wang, Flow due to a stretching boundary with partial slip-an exact solution of the Navier-Stokes equation, Chem. Eng. Sci.2002; 57:3745-3747.

[56] N.A. Halim, R.U. Haq, N.F.M. Noor, Active and passive controls of nanoparticles in Maxwell stagnation point flow over a slipped stretched surface, Meccanica.52(7) (2017) 1527-1539.

[57] M. Norouzi, M. Davoodi, O. Anwar Bég, MD. Shamshuddin, Theoretical study of Oldroyd-B visco-elastic fluid flow through curved pipes with slip effects in polymer flow processing, Int. J. Appl. Comput. Math.2019;4: Article ID:108. https://doi.org/10.1007/s40819-018-0541-7

[58] N.F.M. Noor, R.U. Haq, S. Nadeem,I. Hashim, Mixed convection stagnation flow of a micropolar nanofluid along a vertically stretching surface with slip effects,Meccanica.50 (8) (2015) 2007-2022.

[59] N. Shukla, P. Rana, O. Anwar Bég, S. Bani, A. Kadir, Homotopy study of magnetohydrodynamic mixed convection nanofluid multiple slip flow and heat transfer from a vertical cylinder with entropy generation, Propulsion and Power Res. 8(2) (2019) 147-162.

[60] S. Saleem, M.A. El-Aziz, Entropy generation and convective heat transfer of radiated non-Newtonian power-law fluid past an exponentially moving surface under slip effects, Euro. Phys. J. Plus.134 (2019) 184-195.

[61] C. Shu, Y.T. Chew, Richards BE, Generalized differential-integral quadrature and their application to solve boundary layer equations, Int. J. Numer. Methods in Fluids.21 (1995) 723- 733.

[62] Sun Jian-An, Z.Y. Zheng, Application of differential quadrature method to solve entry flow of viscoelastic second-order fluid, Int. J. Numer. Methods in Fluids.30 (8) (1999) 1109-1117.

[63] C. Shu C, H. Xue,Y.D. Zhu, Numerical study of natural convection in an eccentric annulus between a square outer cylinder and a circular inner cylinder using GDQ method,Int. J. Heat and Mass Transf.44 (17) (2001) 3321-3333.

[64] O. Anwar Bég, Numerical methods for multi-physical magnetohydrodynamics, Chapter 1: New Developments in Hydrodynamics Research, (M. J. Ibragimov and M. A. Anisimov, Eds.,) Nova Science, New York, USA, 2012. pp. 1-112.

[65] A.K. Ray, B. Vasu, O. Anwar Bég, R.S.R. Gorla, P.V.S.N. Murthy, Magnetobioconvection flow of a Casson thin film with nanoparticles over an unsteady stretching sheet: HAM and GDQ computation, Int. J. Numer. Methods for Heat and Fluid Flow 29(11) (2019) 4277-4309.

[66] K.C. Cramer,S.I. Pai, Magnetofluid Dynamics for Engineers and Applied Physicists, MacGraw-Hill, New York, USA, 1973. 
[67] W.F. Hughes,F.J. Young, The Electro-magneto-dynamics of Fluids, John Wiley, New York, USA, 1966.

[68] G.W. Sutton,A. Sherman, Engineering Magnetohydrodynamics. McGraw-Hill Book Company, New York, USA, 1965.

[69] Y. Xin, H. Peng, J. Xu,J. Zhang, Ultra-uniform embedded liquid metal in sulphur polymers for recyclable, conductive, and self-healable materials, Adv. Functional Mat.29 (17) (2019)Article ID:1808989. https://doi.org/10.1002/adfm.201808989.

[70] H. Wang, Y. Yao, Z. He, W. Rao, L. Hu, S. Chen, J. Lin, J. Gao, P. Zhang, X. Sun, X. Wang, Y. Cui, Q. Wang, S. Dong, G. Chen,J. Liu, A highly stretchable liquid metal polymer as reversible transitional insulator and conductor, Adv. Functional Mat.31(23) (2019) Article ID:1901337.https://doi.org/10.1002/adma.201901337.

\section{NOTATION}

B magnetic field vector

$B_{0} \quad$ constant magnetic field

Ec Eckert number

$c_{p} \quad$ specific heat at constant pressure

$C f_{x} \quad$ local skin friction coefficient

$\boldsymbol{E} \quad$ electrical field vector

Ec Eckert number

$f \quad$ dimensionless primary stream function

$g \quad$ dimensionless secondary (crossflow) velocity

$G r_{x} \quad$ local Grashof number

$K \quad$ consistency coefficient

$k \quad$ thermal conductivity of fluid

$L \quad$ characteristic length

$m \quad$ Hall current parameter

$M \quad$ magnetic parameter

$n \quad$ rheological power-law exponent

$N u_{x} \quad$ local Nusselt number

$\mathrm{Pr} \quad$ generalized Prandtl number

$q_{\text {rad }}$ radiative heat flux

$R \quad$ radiation parameter

Re local Reynolds number

$R e_{x} \quad$ generalized local Reynolds number

$T \quad$ fluid temperature

$T_{w} \quad$ temperature at the wall

$T_{\infty} \quad$ ambient temperature of the fluid

$u \quad$ velocity component in the $x$-direction

$U_{0} \quad$ characteristic velocity

$u_{w} \quad$ stretching sheet velocity

$v \quad$ velocity component in the $y$-direction

$w \quad$ velocity component in the $z$-direction

$x \quad$ streamwise coordinate

$y$ cross-stream (transverse) coordinate

\section{Greek symbols}

$\alpha \quad$ thermal diffusivity

$\beta \quad$ volumetric coefficient of the thermal expansion 
$\delta \quad$ mixed convection parameter

$\theta \quad$ dimensionless temperature

$\rho \quad$ fluid density

$\eta \quad$ similarity independent variable

$\lambda \quad$ generalized slip parameter

$\lambda^{*} \quad$ primary hydrodynamic slip coefficient

$\lambda_{1} \quad$ secondary hydrodynamic slip coefficient

$\xi \quad$ mixed convection parameter

$\tau_{w} \quad$ primary wall shear stress

$\psi \quad$ stream function

$\Omega \quad$ dimensionless temperature difference

\section{Subscripts}

$w$ quantities at wall

$\infty$ quantities far away from the surface 